\title{
Development of a Novel Ni-Based Multi-principal Element Alloy Filler Metal, Using an Alternative Melting Point Depressant
}

\author{
LIAM HARDWICK, PAT RODGERS, ED PICKERING, and RUSSELL GOODALL
}

\begin{abstract}
Brazing is a crucial joining technology in industries where nickel-superalloy components must be joined. Nickel-based brazing filler metals are extensively employed, possessing excellent mechanical properties, corrosion resistance, and retained strength at elevated temperatures. To function as a filler metal, the alloy melting point must be reduced to below that of the materials being joined, but the addition of melting point depressants (MPDs) such as boron, silicon, and phosphorus can, however, lead to the formation of brittle intermetallics, potentially compromising the joint performance. In the present work, a novel multi-principal element brazing alloy (in the style of a high entropy alloy), utilizing Ge as an alternative MPD along with a reduced B addition, is investigated. The design process considered binary phase diagrams and predictions based on Thermo-Calc software and empirical thermodynamic parameters. The alloy was used to vacuum braze nickel-superalloy Inconel-718, and microstructural and mechanical investigations are reported. The maximum shear strength achieved was $297 \mathrm{MPa}$ with a brazing temperature of $1100{ }^{\circ} \mathrm{C}$ and 60 -minute hold time, with isothermal solidification completed. Shear strength was only slightly reduced with increased joint width. Assessments are made of the ability to accurately predict properties of multi-principle element alloys using Thermo-Calc software and empirical thermodynamic parameters.
\end{abstract}

https://doi.org/10.1007/s11661-021-06246-0

(C) The Author(s) 2021

\section{INTRODUCTION}

BRAZING has become an important technology for the joining of materials unsuitable for welding, such as nickel superalloys, which could otherwise be susceptible to strain age cracking in the post-weld heat-affected zone. Brazing instead employs a filler metal which melts and bonds the two materials through a diffusion-controlled process. This may be either placed directly in the joint, or applied such that capillary action will draw the molten filler metal into the joint. Current commercially available nickel-based filler metals are preferred for the brazing of nickel-superalloy components in applications demanding high mechanical performance, at elevated temperatures and in corrosive environments. The properties of such alloys are generally achieved by alloying additions including chromium for enhanced corrosion resistance $^{[1]}$ and iron for increased solid solution

LIAM HARDWICK and RUSSELL GOODALL are with the Department of Materials Science \& Engineering, University of Sheffield, Sheffield, UK. Contact e-mail: lhardwick1@sheffield.ac.uk. PAT RODGERS is with the VBC Group, Loughborough, UK. ED PICKERING is with the Department of Materials, University of Manchester, Manchester, UK.

Manuscript submitted September 1, 2020; accepted March 13, 2021.

Article published online April 3, 2021 strengthening. ${ }^{[2]}$ In addition, to enable brazing at a suitably low temperature, elements acting as melting point depressants (MPDs) are added to the brazing alloy in relatively small weight percentages in order to attain a suitable liquidus. The most prevalent of these elements are boron, silicon, and phosphorus.

It is well documented, however, that such additions encourage the formation of undesirable intermetallic phases in the form of borides, silicides, and phosphides, particularly with the elements nickel, chromium, and iron $^{[3-5]}$ whose solubility limit of these elements is typically very low. Figure 1 shows schematically the basic sequence of processes occurring during brazing (or transient liquid phase bonding (TLPB), discussed in detail elsewhere ${ }^{[6]}$ ) of a base metal with a solid filler metal containing an MPD (Figure 1(a)). When the brazing temperature is reached, the filler metal is fully molten (Figure 1(b)), and a widening of the liquid may occur as the composition at the solid/liquid interface is adjusted to that of the solidus/liquidus MPD concentrations (Figure 1(c)). Diffusion of MPD elements at the brazing temperature from the molten filler into the materials being bonded (which, under the definition of brazing, remain solid at the processing temperature) gradually increases the liquidus of the melt, until an elemental concentration is reached locally where the melt begins to solidify at the brazing temperature, a process known as isothermal 


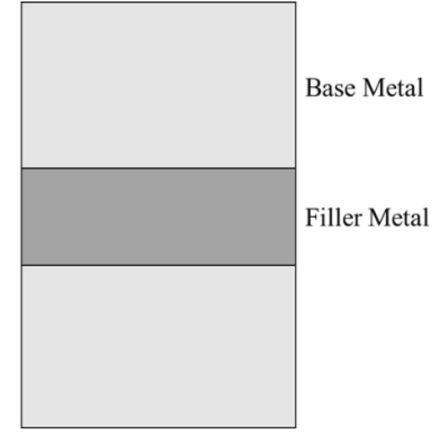

(a)

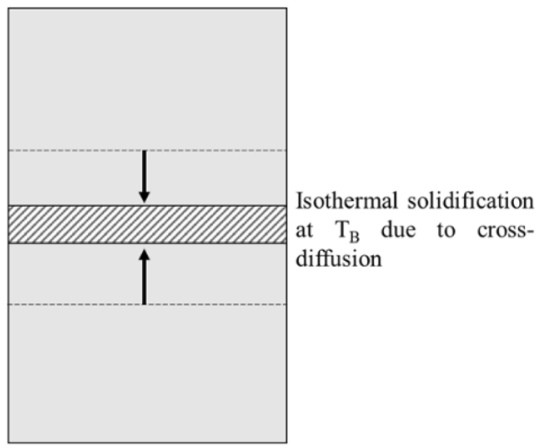

(d)

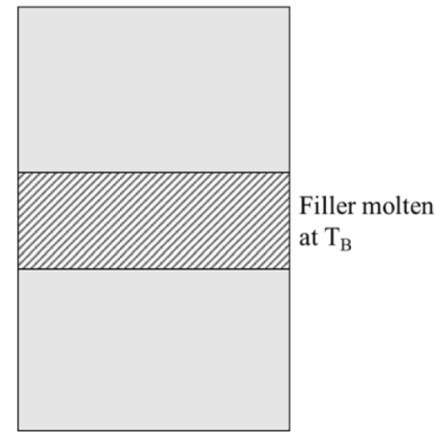

(b)

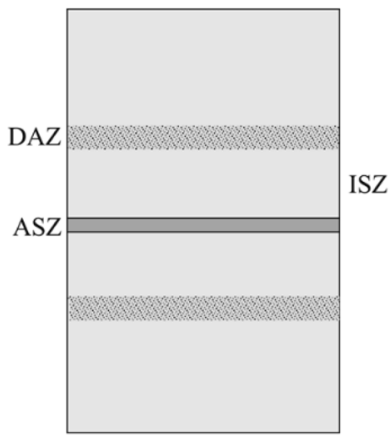

(e)

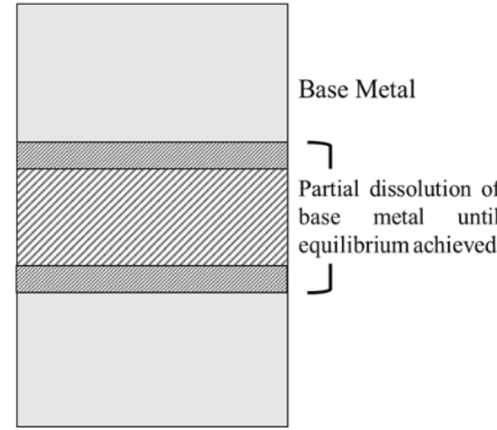

(c)

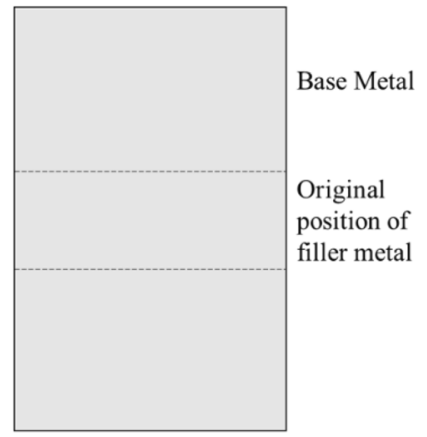

(f)

Fig. 1-Typical stages in brazing; (a) Initial set-up of joint; $(b)$ Molten filler upon reaching $\mathrm{T}_{\mathrm{B}} ;(c)$ Dissolution of base metal and widening of liquid layer; $(d)$ Isothermal solidification stage and reduction of width of liquid layer; $(e)$ remaining DAZ and ASZ as a result of cooling onset before isothermal solidification; $(f)$ Joint where isothermal solidification is allowed to complete before onset of cooling, and DAZ removed via homogenization.

solidification. This occurs as two solidification fronts move inwards from the interfaces with the base material (Figure 1(d)). When the time at the brazing temperature is not sufficient for isothermal solidification of the entire joint, and the onset of cooling follows, brittle intermetallic phases can form via eutectic transformation of the remaining melt, enriched in these elements due to their low solubility in the advancing gamma matrix phase, usually occurring along the joint center. ${ }^{[7,8]} \mathrm{A}$ joint examined at this stage may exhibit two phenomena often referred to as the isothermally solidified zone (ISZ), and the athermally solidified zone (ASZ). Furthermore, fast diffusing elements such as boron can react with the base metal elements, creating what is commonly referred to as a diffusion-affected zone (DAZ) at the interface of filler metal and into the base metal, ${ }^{[9,10]}$ which may remain even if isothermal solidification is complete within the joint. These phenomena are represented in Figure 1(e). In addition, providing a potentially continuous crack propagation path, reacting with base metal elements such as $\mathrm{Cr}, \mathrm{Nb}$, and Mo can result in their diminished concentration within the base metal matrix, and thus reduce the corrosion resistance locally. When sufficient time at the brazing temperature is allowed, however, isothermal solidification may progress fully across the joint. Further homogenization heat treatments following brazing may be used to remove the DAZ through further diffusion, as is typically the final stage in TLPB. In this case, a brazed joint may be largely indistinguishable from the original base metal, as in Figure 1(f). In total, the inclusion of the current MPD elements in concentrations used in current brazing alloys can cause increased brittleness and ultimately premature failure in the joint ${ }^{[11-13]}$ without the use of either prolonged brazing cycles or post-braze heat treatments, both of which are economically undesirable, and may present practical challenges.

The majority of studies into viable alternative MPDs involve exploration of the addition of a single alternative MPD element to nickel. Dinkel et al. (2008) investigated the use of Ge as a potential MPD in binary $\mathrm{Ni}-\mathrm{Ge}$ alloys, for brazing superalloys PWA 1483 and René N5 with Ni-23wt pet Ge and Ni-20wt pet Ge, respectively. ${ }^{[14]}$ With joint gaps reported as $200 \mu \mathrm{m}$, for the first alloy 48 hours at $1160{ }^{\circ} \mathrm{C}$ was required for gap closure, and 24 hours at $1180{ }^{\circ} \mathrm{C}$ for the second alloy. Laux et al. (2008) trialed a range of Ni-Mn (36.7 and 58.4 wt pet $\mathrm{Mn}$ ) and Ni-Mn-Si (20wt pet Mn-2wt pet Si, 20 wt pet $\mathrm{Mn}-3$ wt pet $\mathrm{Si}$, and 25 wt pet $\mathrm{Mn}-2$ wt pet $\mathrm{Si}$ ) alloys for the wide-gap brazing of a Ni-7.5Co-7.0 Cr-1.5Mo-5.0W-6.5Ta-6.2Al-3.0Re (in wt pet) superalloy. ${ }^{[15]}$ For constant brazing hold times of 30 minutes, brazing temperatures ranged from $1040{ }^{\circ} \mathrm{C}$ for the highest $\mathrm{Mn}$ content (Ni-58.4Mn in wt pct) to $1260{ }^{\circ} \mathrm{C}$ for the lowest Mn content (Ni-20Mn-2Si in wt pct). Evidently, such alloys often require substantial amounts of the proposed MPD, yet the liquidus temperature is often still considerably higher than for most current nickel-based brazing filler metals (which would typically be between $1000{ }^{\circ} \mathrm{C}$ 
and $1150{ }^{\circ} \mathrm{C}$ ). There is motivation, therefore, to seek novel compositions that can achieve a strong joint, free of brittle intermetallic phases within typical industrial brazing cycles.

In recent years, significant attention has been paid to high entropy alloys (HEAs), a relatively new class of materials comprising typically 5 or more elements, in roughly equiatomic proportions or concentrations originally defined as 5 to 35 at pct. ${ }^{[16]}$ They are so-named due to the supposed role that their enhanced configurational entropy plays on their potentially unique properties. More recently, the definition of HEAs has undergone some broadening, extending to non-equiatomic compositions, or systems with as few as three elements. ${ }^{[17]}$ Such systems are sometimes referred to generally as multi-principal element alloys (MPEAs). ${ }^{[18,19]}$ Often based on transition and/or refractory metals, HEAs and MPEAs have proved of interest due to their potentially exceptional mechanical properties ${ }^{[20-22]}$ and corrosion resistance ${ }^{[23-25]}$; properties which could be of clear benefit to brazing applications. However, perhaps due to both the typically high melting point of such systems (although melting temperature often tends to decrease towards equiatomic compositions), and little or no attempts at designing for a melting temperature relevant to brazing (through refining composition or and/ or use of a MPD element), relatively little has been published on employing HEAs as brazing filler metals. From those studies that do exist, the brazing temperature required is often significantly higher than typically used for current brazing filler metals. Bridges et al. (2017) demonstrated laser brazing of IN718 superalloy with a Ni-Mn$\mathrm{Fe}-\mathrm{Co}-\mathrm{Cu} \mathrm{HEA}$, at a brazing temperature of $1165^{\circ} \mathrm{C}$ and achieving a $220 \mathrm{MPa}$ maximum shear strength. ${ }^{[26]}$ Tillmann et al. (2018) joined Hf-metallized YSZ ceramic to Crofer 22 APU steel using a Nb-Co-Cr-Fe-Ni HEA, achieving almost double the shear strength than when using a typical AgCuTi3 filler metal, albeit at a brazing temperature of $1200{ }^{\circ} \mathrm{C}$, some $280{ }^{\circ} \mathrm{C}$ higher than that for AgCuTi3. ${ }^{[27]}$ Gao et al. (2019) demonstrated a maximum shear strength of $530 \mathrm{MPa}$ when joining IN600 superalloy with a $\mathrm{Fe}-\mathrm{Co}-\mathrm{Ni}-\mathrm{Mn}-\mathrm{Cu} \mathrm{MPEA}$, with a brazing hold time of 90 minutes at $1200{ }^{\circ} \mathrm{C}$. $^{[28]}$

The present work therefore demonstrates an alloy design process, with the aim of developing a novel HEA or MPEA-derived filler metal composition able to produce superior joints when used within typical industrial brazing cycles. This process employs binary and ternary phase diagrams, empirical thermodynamic parameters used in the design of HEAs, and ThermoCalc software (SSOL4 database), which uses the CALPHAD method of extrapolating thermodynamic information of a system from experimentally verified data on binary and ternary systems.

\section{PRELIMINARY ALLOY DESIGN STUDY}

It is clear from binary $\mathrm{Ni}$ phase diagrams and the literature $[14,15]$ that, of numerous candidate MPD elements (transition and post-transition metals, metalloids, and refractories), most would require excessive atomic percentages (compared to that of $\mathrm{B}$ or $\mathrm{Si}$ ) to achieve a liquidus comparable to current B/Si-containing filler metals; in many cases 30 at. pct or more of addition would be needed. In other cases, the liquidus may still be over $150^{\circ} \mathrm{C}$ above that of $\mathrm{B} / \mathrm{Si}$-containing filler metals. In this study, Ge was considered as an alternative MPD. According to the Ni-Ge binary phase diagram (Figure 2(a)), a liquidus of $1125^{\circ} \mathrm{C}$ is achieved with 22 at. pct Ge, ${ }^{[29]}$ hence a reasonable MPD effect is exhibited. Ge also exhibits a greater solubility in $\mathrm{Ni}$ than $\mathrm{B}$ or $\mathrm{P}$, at approximately 13 at. pet at $1125^{\circ} \mathrm{C}$, which is closer to that of $\mathrm{Si}$ at 14.6 at. pct. As reported in the phase diagram ${ }^{[29]}$ a gamma-prime $\left(\gamma^{\prime}\right)$ phase is formed at compositions between approximately 23 and 26 at. pct Ge, which could enhance mechanical properties of the joint through a similar mechanism to the $\gamma$ ' phase in standard nickel superalloys. Clearly, however, the use of $\mathrm{Ge}$ as a like-for-like substitute for $\mathrm{B}$ or $\mathrm{Si}$ in a conventional Ni-based filler metal, despite any potential microstructural improvements in the form of gammaprime precipitates, would not achieve a liquidus similar to those of many current commercial brazing alloys. While increasing the at. pct of Ge in any developed alloy may well further reduce the liquidus and hence brazing temperature, this increases the risk of brittle intermetallic formation.

However, according to the liquidus projection in the Cr-Fe-Ni ternary system, as shown in Figure $2(\mathrm{~d}),{ }^{[32]}$ the liquidus decreases towards the equiatomic composition, reaching $1390{ }^{\circ} \mathrm{C}$ at approximately equiatomic concentrations. In addition, $\mathrm{Ni}, \mathrm{Cr}$, and $\mathrm{Fe}$ are chemically compatible with a superalloy base metal, and exhibit an extended mutual solubility range, providing an intermetallic-free, lower liquidus matrix to which less Ge may be added than may otherwise be required. Figure 2(b) and Figure 2(c) show the binary phase diagrams for the $\mathrm{Cr}-\mathrm{Ge}^{[30]}$ and $\mathrm{Fe}-\mathrm{Ge}^{[31]}$ binary systems, respectively. As is the case in the Ni-Ge binary system, at high Ge contents, numerous intermetallic phases form with $\mathrm{Cr}$ and $\mathrm{Fe}$, though it can also be seen that $\mathrm{Ge}$ has a similar effect on the liquidus of the $\mathrm{Cr}-\mathrm{Ge}$ $\left(1564{ }^{\circ} \mathrm{C}\right.$ at approximately 25 at. pct Ge) and Fe-Ge $\left(1105^{\circ} \mathrm{C}\right.$ at approximately 30 at. pet Ge) binary systems, and exhibits somewhat similar solubility (11 and 16 at. pct $\mathrm{Ge}$, respectively). An increased $\mathrm{Fe}$ content may also confer cost benefits to the filler metal. Data on the diffusivity of $\mathrm{Ge}$ in $\mathrm{Ni}$ and Ni-superalloys exist ${ }^{[33]}$ and so with an appropriate brazing cycle sufficient Ge diffusion may take place such that the remaining $\mathrm{Ge}$ in the joint is soluble in a superalloy-like Ni-Cr-Fe joint matrix.

In light of this, the addition of Ge to an initially equiatomic $\mathrm{Ni}-\mathrm{Cr}-\mathrm{Fe}$ ternary system was considered, utilizing both Thermo-Calc (TC) software, as well as empirical thermodynamic parameters used in the design of HEAs; the average enthalpy of mixing of binary pairs $\left(\Delta \mathrm{H}_{\text {mix }}\right)$; the average atomic size mismatch $(\delta \mathrm{r})$; and the average valence electron concentration (VEC). TC software may be useful in predicting the melting temperature of a developed filler metal. Considering typical brazing cycles used in industry and the liquidus temperatures of many commercial Ni-based filler metals, it was deemed necessary to aim for a filler metal liquidus 


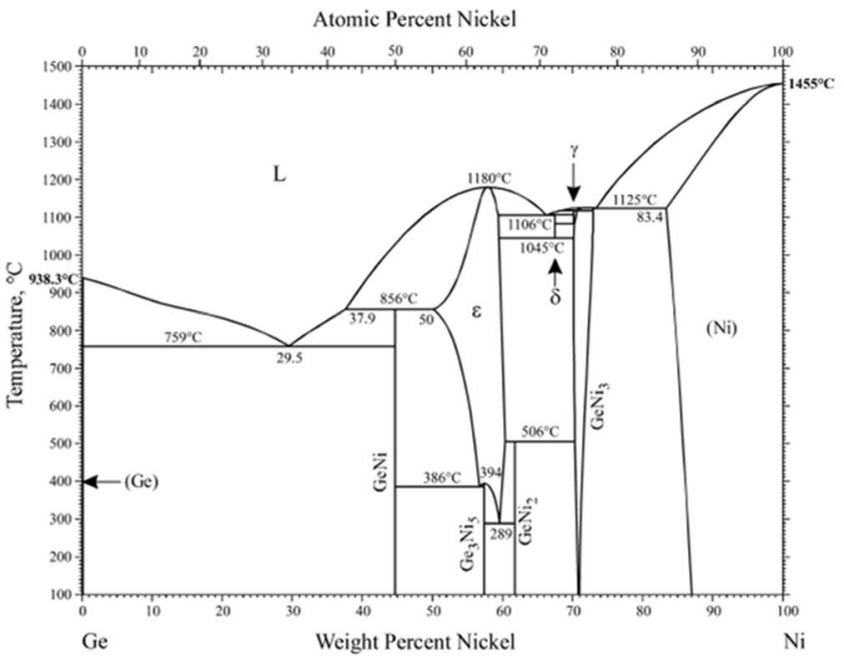

(a)

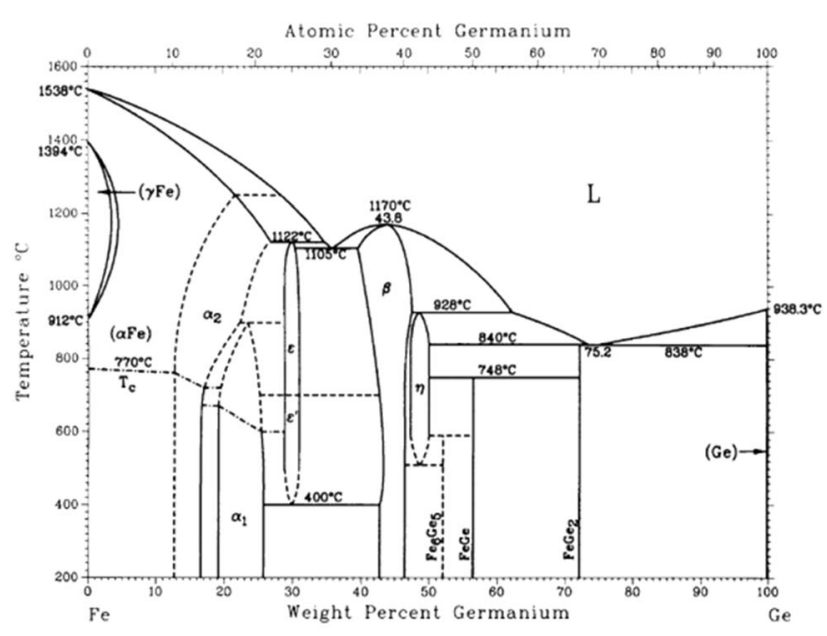

(c)

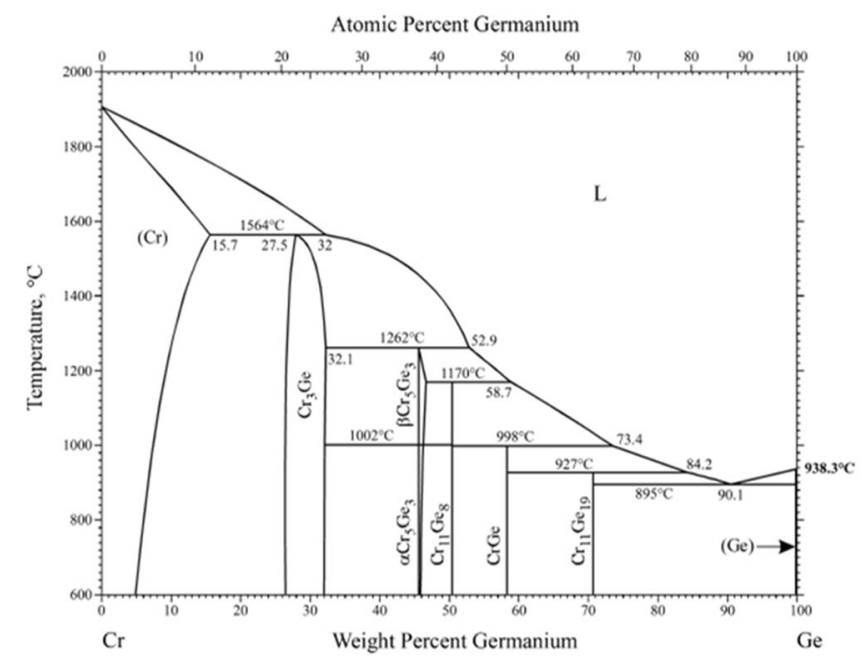

(b)

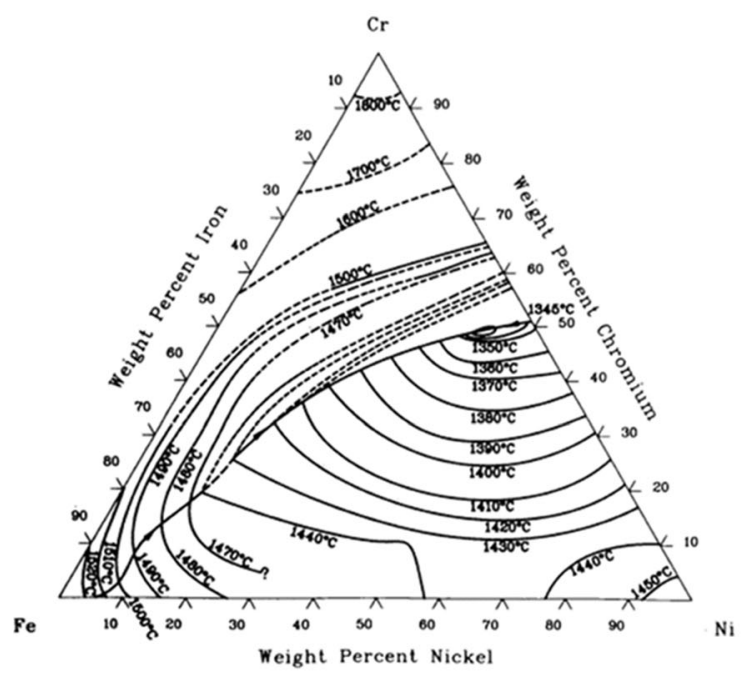

(d)

Fig. 2-(a) Ni-Ge binary phase diagram; (b) Cr-Ge binary phase diagram; (c) Fe-Ge binary phase diagram; $(d)$ Ni-Cr-Fe ternary liquidus projection.

of no higher than $1100{ }^{\circ} \mathrm{C}$. For sufficient ductility in the joint, and in order to more closely match the base metal FCC matrix, it was considered that the developed filler metal should ideally possess a predominantly FCC microstructure. The empirical thermodynamic parameters could aid in predicting the microstructure. In keeping with classic guidelines based on the Hume-Rothery rules, it has been suggested that minimizing $\left|\Delta \mathrm{H}_{\text {mix }}\right|$ promotes the formation of solid solution, with negative or positive values promoting intermetallic formation or segregation, respectively. ${ }^{[34]}$ The expression for $\left|\Delta \mathrm{H}_{\text {mix }}\right|$ is given in Eq. [1]:

$$
\Delta H_{m i x}=\sum_{i=1}^{n} \sum_{j>i}^{n} \Omega_{i j} c_{i} c_{j}=\sum_{i=1}^{n} \sum_{j>i}^{n} 4 H_{m i x}^{i j} c_{i} c_{j}
$$

where $H_{m i x}^{i j}$ is the mixing enthalpy (in $\mathrm{kJ} \mathrm{mol}^{-1}$ ) of the binary pair of elements $i$ and $j$, and $c_{i}$ and $c_{j}$ are the atomic concentrations of elements $i$ and $j$, in an $\mathrm{n}$ component system. Similarly, a small $\delta \mathrm{r}$ is considered beneficial for promoting solid solution. ${ }^{[34,35]}$ The expression for $\delta \mathrm{r}$ is given in Eq. [2]:

$$
\delta r=\sqrt{\sum_{i=1}^{n} c_{i}\left(1-\frac{r_{i}}{\bar{r}}\right)^{2}}
$$

where $r_{i}$ is the atomic radius of element $i$ and $\bar{r}$ is the average atomic radii of all elements in the $n$ component system, and $c_{i}$ is the atomic concentration of element $i$. In other studies, it is suggested that the average VEC can be used to predict crystal structure of the solid solution. The expression for the average VEC is given in Eq. [3]:

$$
V E C=\sum_{i=1}^{n} c_{i} V E C_{i}
$$

where $V E C_{i}$ is the VEC of the element $i$, and $c_{i}$ is again the atomic concentration of element $i$, in an $n$ component system. Higher VEC is associated with FCC and 
lower with BCC (though the exact threshold values differ between systems). ${ }^{[36,37]}$ For example, it is suggested that an average VEC of over 8 , or below 6.87 , would favor promotion of a FCC or BCC microstructure, respectively. ${ }^{[36,37]}$ For $8 \geq \mathrm{VEC} \geq 6.87$, both FCC and $\mathrm{BCC}$ phases would be present.

\section{ALLOY DESIGN RESULTS}

Figure 3 shows the TC property diagram for the equiatomic $\mathrm{NiCrFeGe}$ system, exhibiting solidus and liquidus temperatures of $900{ }^{\circ} \mathrm{C}$ and $1110^{\circ} \mathrm{C}$, respectively. The TC predictions show a multi-phase microstructure upon solidification to room temperature, but with a desirable FCC majority phase. Promotion of the primary FCC phase was possible by moving away from the equiatomic composition, but this resulted in an increase in the predicted liquidus temperature. A predicted compromise between increased FCC content and decreased liquidus content could be achieved for a $\mathrm{Ni}$ (bal.)-Cr(15.6)-Fe(29.5)-Ge(25) at. pct composition, but the predicted liquidus was still higher than in the equiatomic case, and so neither composition was deemed of interest for this study.

Indeed, it was found that, except at Ge concentrations of approximately 30 at. pet and higher, a sub-1100 ${ }^{\circ} \mathrm{C}$ liquidus was not predicted to be achieved in the $\mathrm{NiCrFeGe}$ system. Given both the need for good chemical compatibility with a prospective Ni-based superalloy, and the high raw cost of $\mathrm{Ge}$, it was, however, deemed necessary to limit the Ge content to 25 at. pct and to ensure that no one element is present in a higher concentration than Ni. Boron, as discussed, is widely employed as an MPD in nickel-based filler metals and is well known as a fast diffusing element in nickel-based superalloys. It can therefore be conceived

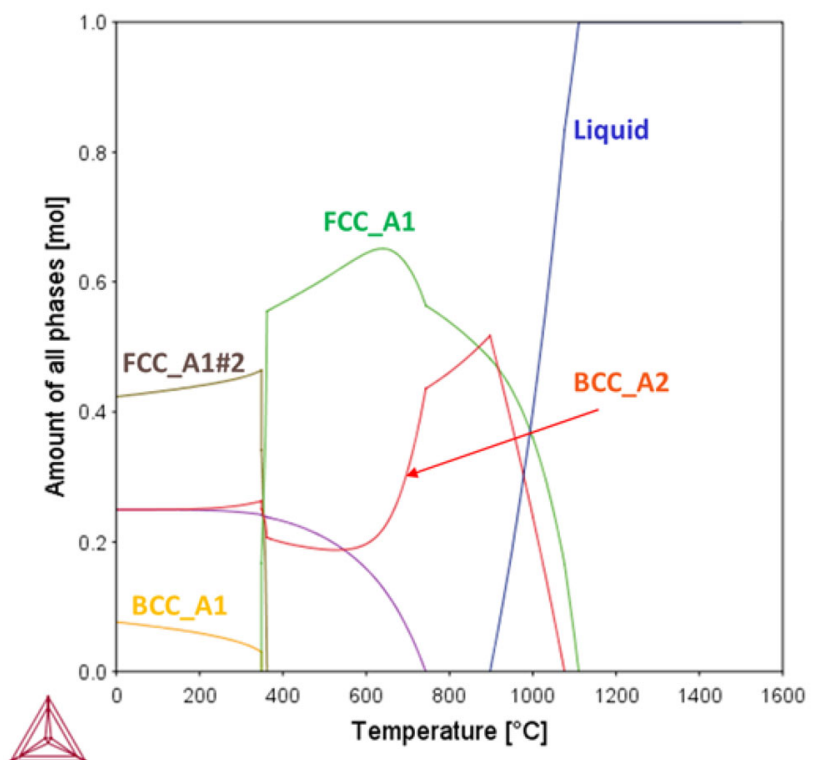

Fig. 3-Thermo-Calc diagram showing predicted proportion of phase as a function of temperature for the equiatomic $\mathrm{NiCrFeGe}$ composition. that an appropriately small amount of B (compared to current commercially available options that utilize B as MPD) contained by the developed filler metal may sufficiently reduce the liquidus temperature, and during brazing diffuse away from the joint over the course of an appropriate brazing cycle, leaving behind a HEA or MPEA-like central joint region. Initially, a B content of between 0 and 5 at. pct was therefore considered as an addition to the equiatomic $\mathrm{NiCrFeGe}$ system, while noting the additional need to consider the boride content now predicted by TC. A suitable predicted liquidus temperature was achieved at 2.5 at. pct $\mathrm{B}$, giving solidus and liquidus temperatures of $840{ }^{\circ} \mathrm{C}$ and $1038^{\circ} \mathrm{C}$, respectively, with $\mathrm{TC}$ predicting a low $\mathrm{CrB}$ content of $7.5 \mathrm{~mol}$ pet (in comparison, for $\mathrm{BNi}-2, \mathrm{TC}$ predicts approximately 13 and $15 \mathrm{~mol}$ pet of $\mathrm{Cr}_{2} \mathrm{~B}$ and $\mathrm{Ni}_{2} \mathrm{~B}$, respectively). This $\mathrm{B}$ concentration is significantly lower than contained in, for example, BNi-2 which has approximately 14 at. pct B.

Upon further optimization of the composition (in terms of predicted liquidus temperature, predicted FCC content, and predicted boride content), this alloy design approach resulted in the development of a Ni-rich off-equiatomic MPEA with a composition (in at. pct) of $\mathrm{Ni}(30.5)-\mathrm{Cr}(25)-\mathrm{Fe}(18)-\mathrm{Ge}(24)-\mathrm{B}(2.5)$. Predicted solidus and liquidus temperatures for this composition were $820^{\circ} \mathrm{C}$ and $1062{ }^{\circ} \mathrm{C}$, with a primary FCC matrix and predicted $\mathrm{Cr}$-boride molar concentration of under 10 pct. The TC predicted phase diagram for this composition is shown in Figure 4. The predicted properties of the above series of alloy compositions are summarized in Figure 5.

Investigating the constitution of these predicted phases, the primary FCC phase was predicted to consist of only a Ni-37at. pct Fe solid solution, whereas the $\mathrm{Cr}$ and Ge contents were predicted to be completely segregated in the microstructure, showing as BCC_A2

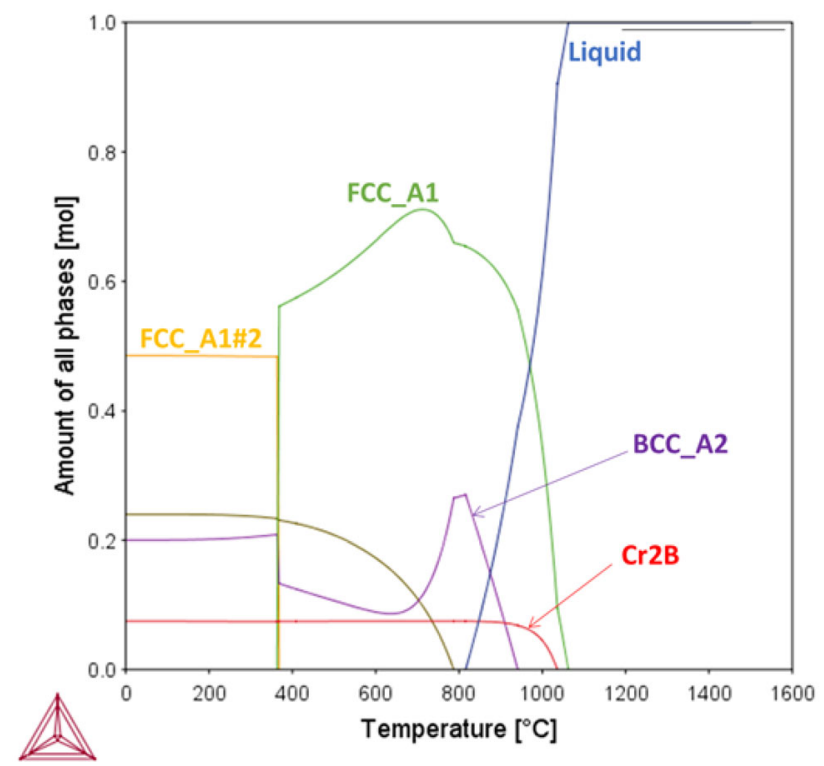

Fig. 4-Thermo-Calc diagram showing predicted proportion of phase as a function of temperature for the final $\mathrm{Ni}(30.5)-\mathrm{Cr}(25)-\mathrm{Fe}(18)-\mathrm{Ge}(24)-\mathrm{B}(2.5)$ composition. 


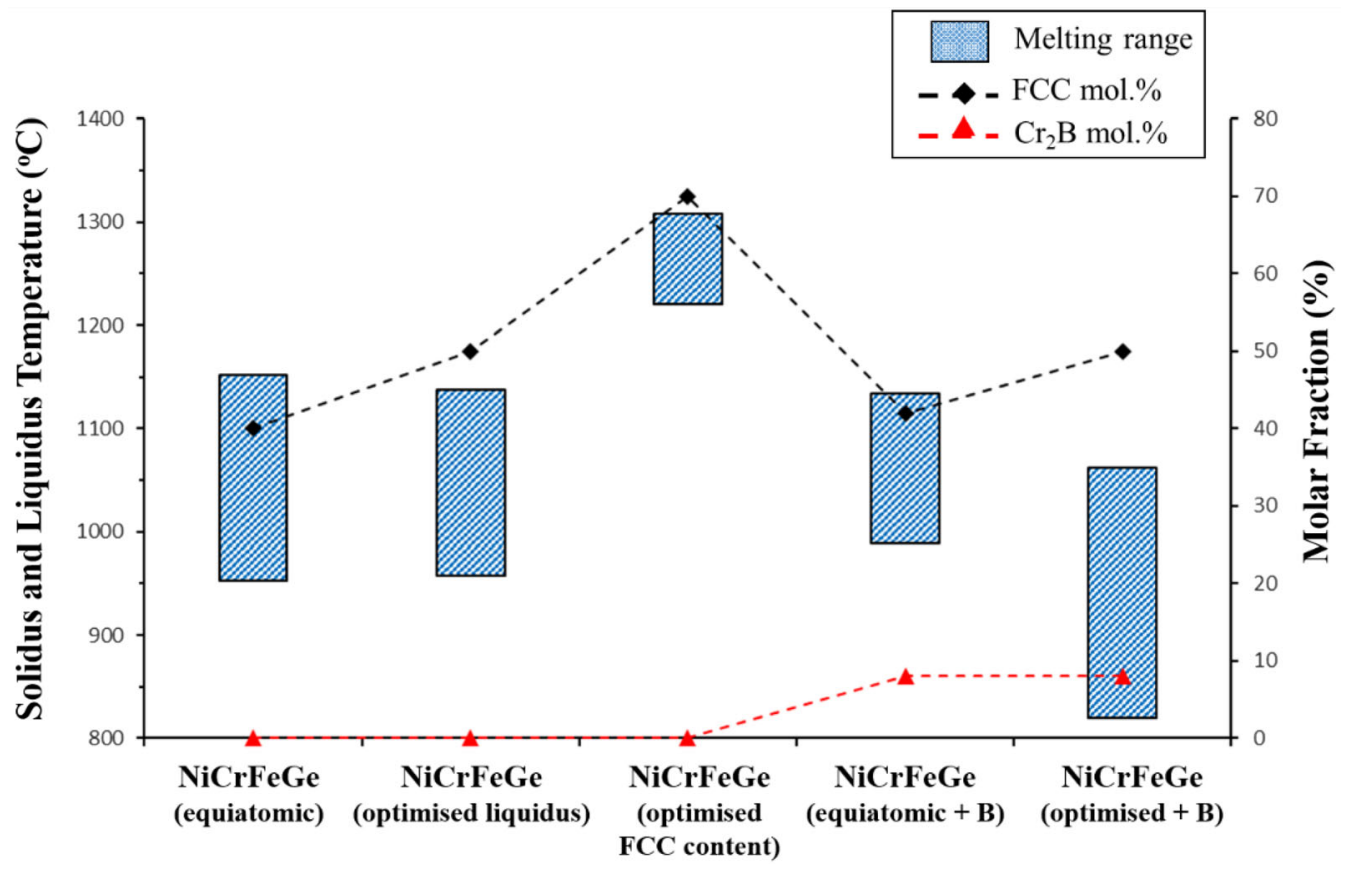

Fig. 5- Chart summarizing Thermo-Calc-predicted melting range, FCC mol pct and $\mathrm{Cr}_{2} \mathrm{~B}$ mol pct of each alloy composition throughout the design process.

and DIAMOND_A4, respectively, in Figure 4, which may be attributed to the lack of assessed Ge binary or ternary systems data in the SSOL4 database. At the same time, the SGTE Solutions SSOL databases are the only current databases to cover all the elements in the present composition. Rather, the previously mentioned empirical thermodynamic parameters, shown in Table I, were also considered. For the $\mathrm{Ni}(30.5)-\mathrm{Cr}(25)-\mathrm{Fe}(18)-$ $\mathrm{Ge}(24)-\mathrm{B}(2.5)$ composition, it can be seen that the average VEC tends towards favoring mixed BCC/FCC formation, but that $\left|\Delta \mathrm{H}_{\text {mix }}\right|$ is also minimized compared to the other compositions. It must be noted here that such trends between microstructure and these parameters arise from the screening of numerous HEAs, and is mainly based only on transition and refractory metals, and very little has been established for cases of mixed transition metal-metalloid systems such as this. Table I summarizes the development of the composition in terms of the empirical thermodynamic parameters.

\section{EXPERIMENTAL PROCEDURE}

Pure elements (of at least 99.9 pct purity, Alfa Aesar) were arc-melted in an Arcast 200 Arc-melter, producing an ingot of the $\mathrm{NiCrFeGeB}$ alloy of approximately $20 \mathrm{~g}$ in a water-cooled copper crucible. The operating current was $450 \mathrm{~A}$, and the ingot was flipped and re-melted five times to improve homogeneity, with electromagnetic stirring also applied for this reason. An 8-mm $\varnothing$ cylinder of length $10 \mathrm{~mm}$ was removed from the as-cast ingot via electron discharge machining. Thin slices (400 to 800 $\mu \mathrm{m})$ were then sectioned from this cylinder, which were then manually ground with the aim of achieving a thickness of $50 \mu \mathrm{m}$ (in line with common foil thickness of commercial filler metals such as AWS BNi-2) using a stainless steel grinding jig and $\mathrm{SiC}$ grit papers. Due to difficulties with foil breakage before reaching $50 \mu \mathrm{m}$ thickness, a foil thickness of approximately $65 \mu \mathrm{m}$ was instead achieved. A further slice was ground to a thickness of approximately $100 \mu \mathrm{m}$ in order to demonstrate the effect of increased gap size for the developed composition.

The $\mathrm{NiCrFeGeB}$ foils were used to vacuum braze 8 $\mathrm{mm} \varnothing, 5$-mm-length cylinders of Inconel-718 (IN718) to $25 \times 25 \times 5 \mathrm{~mm}$ sheets of IN718. A schematic of the brazed joint is shown in (Figure 6(a)). Brazing was performed at $1100{ }^{\circ} \mathrm{C}$ for 15 (for $65 \mu \mathrm{m}$ thickness) and 60 (for $65 \mu \mathrm{m}$ and $100 \mu \mathrm{m}$ thickness) minutes. In each case, a 15-minute equalization hold was performed at $1010^{\circ} \mathrm{C}$ below the brazing temperature. After brazing, the joints were furnace cooled to $900{ }^{\circ} \mathrm{C}$ before gas quenching. Ramp rates were $15^{\circ} \mathrm{C} \mathrm{min}-1$ in each trial. The same brazing cycles were repeated for AWS BNi-2 in melt-spun foil form of $50 \mu \mathrm{m}$ thickness (VBC Group, Loughborough, UK) for mechanical comparison. Prior to brazing, all IN718 pieces were ground with P1200 papers, before ultrasonic cleaning in acetone for 10 minutes along with the $\mathrm{NiCrFeGeB}$ and $\mathrm{BNi}-2$ foils. A load of $20 \mathrm{~g}$ was placed on each joint during the brazing cycles. Shear testing of the brazed joints through applying compression was performed based on the method of Matsu et al. ${ }^{[38]}$ with the aid of an EN30B steel test fixture (shown schematically in Figure 6(b)). In addition, in order to observe any microstructural changes induced under approximate service conditions (as superalloys are normally used at elevated temperatures for extended times), a 5-mm-length section of a joint brazed at $1100{ }^{\circ} \mathrm{C}$ for 60 minutes was heat treated in an inert atmosphere at $700{ }^{\circ} \mathrm{C}$ for 100 hours. 
Table I. Calculated Empirical Thermodynamic Parameters $\Delta \mathrm{H}_{\mathrm{mix}}$, $\delta$ r, and VEC for Each Alloy Composition Throughout the Design Stage

\begin{tabular}{lcccc}
\hline Parameter & $\begin{array}{c}\text { NiCrFeGe } \\
\text { (Equiatomic) }\end{array}$ & $\begin{array}{c}\text { NiCrFeGe (Optimized } \\
\text { for FCC) }\end{array}$ & $\begin{array}{c}\text { NiCrFeGe (Equiatomic) }) \\
2.5 \text { at pct B }\end{array}$ & Ni(bal.)-Cr(25)-Fe(18)-Ge(24)-B(2.5) \\
\hline $\begin{array}{l}\Delta \mathrm{H}_{\text {mix }}(\mathrm{kJ} \\
\left.\text { mol }^{-1}\right)\end{array}$ & 7.75 & -4.00 & 5.60 & 3.00 \\
$\delta \mathrm{r}$ & 2.85 & 3.98 & 3.60 & 3.98 \\
$\mathrm{VEC}$ & 7.00 & 7.3 & 6.8 & 7.0 \\
\hline
\end{tabular}

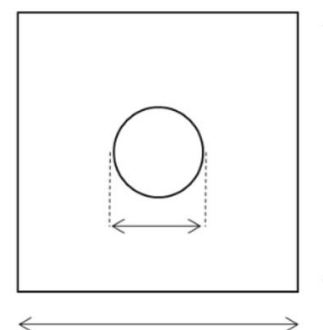

25

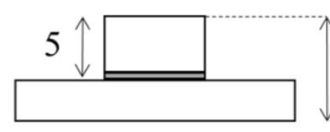

(a)
25

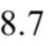

8.7
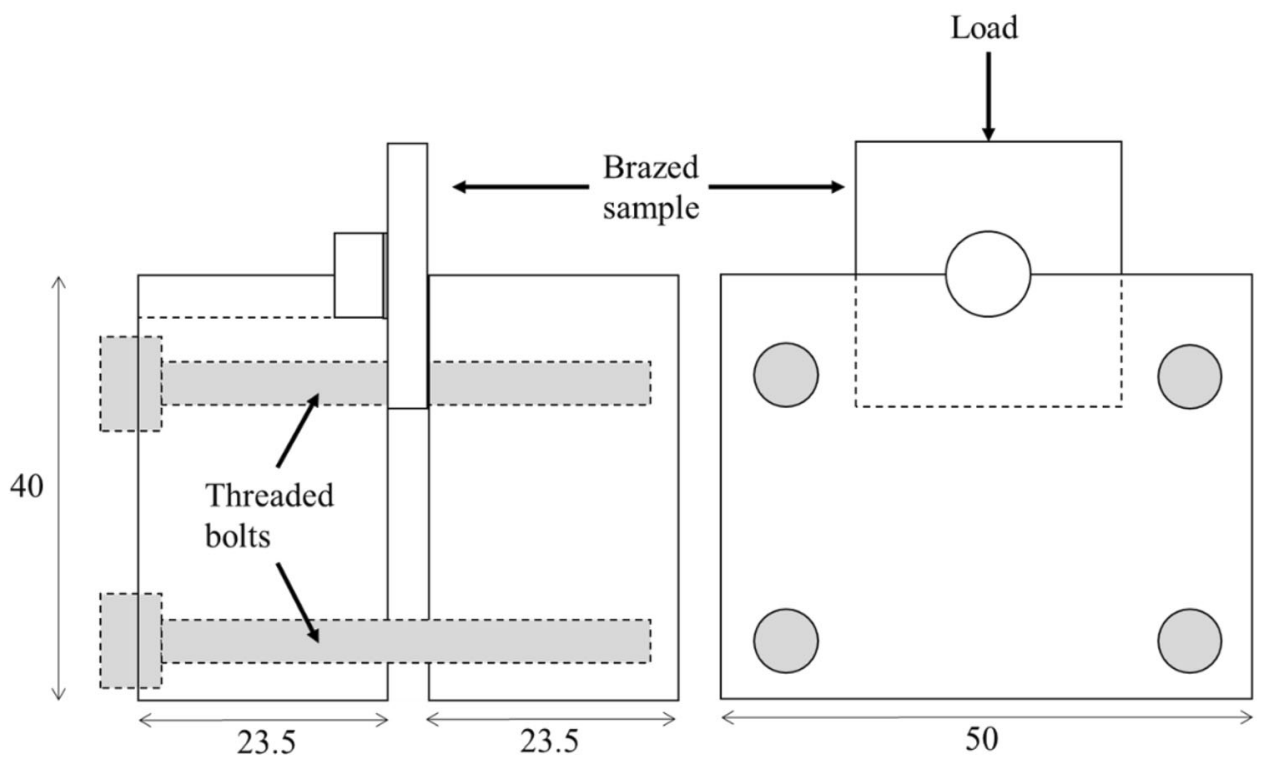

(b)

Fig. 6 - (a) Schematic of brazed joint specimen; (b) Schematic of steel fixture used to seat brazed joint specimen for shear testing.

The composition of the as-cast $\mathrm{NiCrFeGeB}$ alloy was measured via X-ray fluorescence (XRF) (PANalytical Zetium), and phase analysis was performed by X-ray diffraction (Bruker D2 Phaser). Microstructural investigation of the as-fabricated alloys was performed via SEM (BSE) (FEI Inspect F50 operated at $20 \mathrm{keV}$ ) and energy dispersive spectroscopy (EDS) using Aztec software. Differential Scanning Calorimetry (DSC) of a 30 mg sample of the as-cast $\mathrm{NiCrFeGeB}$ alloy was performed in an argon atmosphere with heating and cooling rate of $20^{\circ} \mathrm{C} \mathrm{min}{ }^{-1}$ (Netzsch $404 \mathrm{~F} 1$ Pegasus). Three DSC cooling curves were obtained, with the first discarded in case of insufficient sample contact with crucible, and the second and third averaged. The $\mathrm{NiCrFeGeB}$ brazed joints were imaged via SEM. Further elemental distribution analysis was performed by Electron Probe Micro-Analysis equipped with Soft X-ray Emission Spectrometer (EPMA-SXES) (JEOL JXA-8530F). Microhardness measurements of the as-fabricated alloys and $\mathrm{NiCrFeGeB}$ brazed joints were performed using a Struers Durascan, with a dwell time of 15 seconds. $1 \mathrm{~kg}$ load was used for the as-cast sample, and $50 \mathrm{~g}$ load was used for hardness profiles of the joints post-braze.

\section{RESULTS}

\section{A. As-Cast $\mathrm{NiCrFeGeB} \mathrm{Alloy}$}

The typical as-cast $\mathrm{NiCrFeGeB}$ microstructure SEM micrograph is shown in Figure 7(a), along with EDS maps showing the elemental distribution (Figure 7(c)). Four distinct phases were observed; a fine needle-like phase (black contrast) between 50 and $200 \mu \mathrm{m}$ length (marked 1); an irregular-shaped phase (dark gray contrast), approximately $20 \mu \mathrm{m}$ in size (marked 2); and upon increasing magnification (Figure 7(b)) two further phases (medium and light gray contrast, respectively) (marked 3 and 4). The needle-like dark phase is most likely a chromium-rich boride (known difficulties in detecting light elements via EDS means boron concentration may be inaccurate), containing also some amount of $\mathrm{Fe}$. The more irregular dark gray phase was found to be more complex, primarily containing chromium but with significant germanium content, as well as iron. The medium and light gray phases were found to contain all nickel, chromium, iron, and germanium, with the light gray being more Ge-rich and the medium gray more Ni-rich. The composition in atomic percent of each phase is reported in Table II, as 


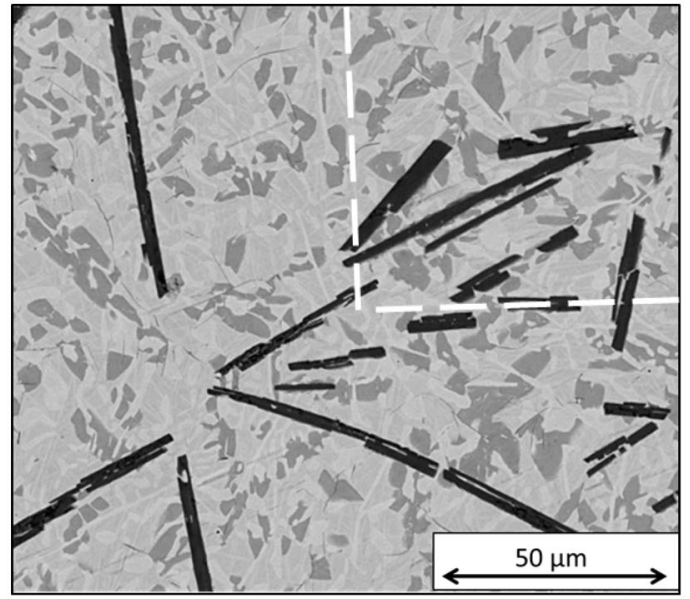

(a)

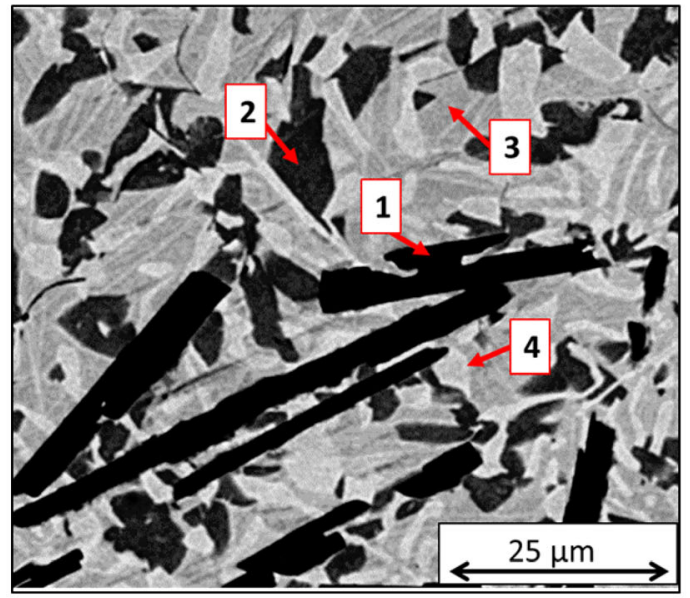

(b)
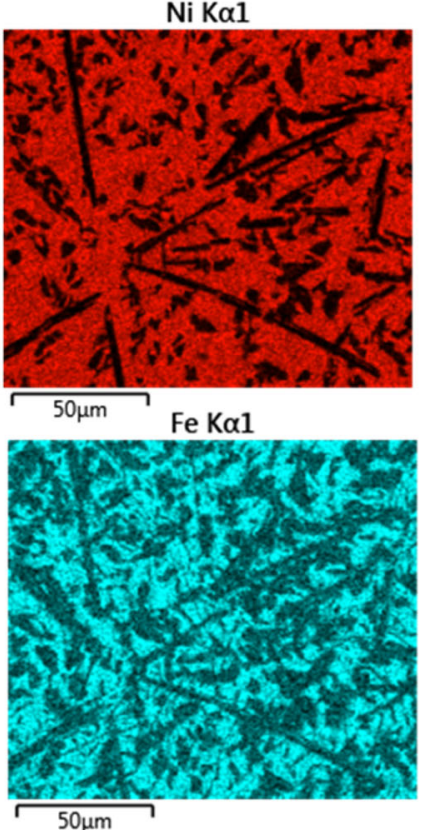
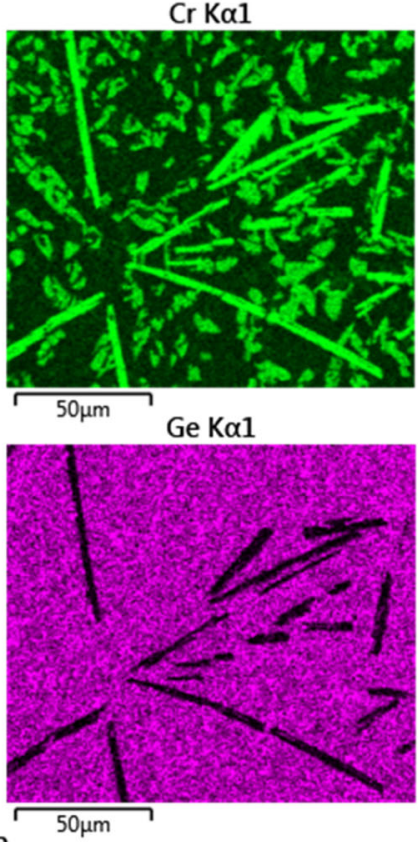

$\mathrm{B} \mathrm{K \alpha} 12$

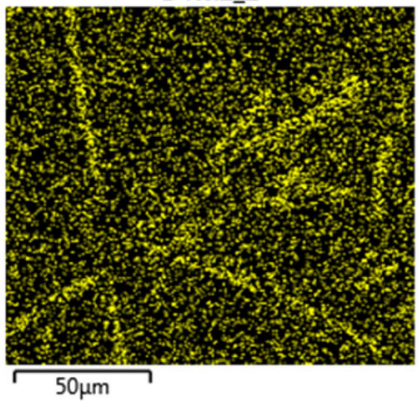

(c)

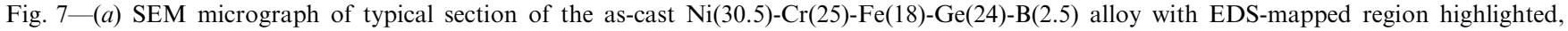
(b) Magnified micrograph of EDS-mapped region highlighted and distinct phases marked 1-4, (c) EDS maps of region shown in (b), showing elemental distribution.

Table II. EDS-Determined (Average of 5-Point Measurements) Composition of Phases Identified in Fig. $7 a$. Errors Derived From Standard Deviation of Measurements

\begin{tabular}{crrrrr}
\hline & \multicolumn{5}{c}{ Element concentration (at. pct) } \\
\cline { 2 - 6 } Phase & \multicolumn{1}{c}{$\mathrm{Ni}$} & $\mathrm{Cr}$ & \multicolumn{1}{c}{ Fe } & Ge & B \\
\hline 1 & 0.8 & 66.5 & 8.3 & 0.6 & 23.7 \\
2 & 3.5 & 63.8 & 10.2 & 22.6 & - \\
3 & 34.0 & 11.4 & 26.3 & 27.6 & - \\
4 & 34.4 & 16.5 & 9.8 & 36.0 & - \\
\hline
\end{tabular}

the average of five EDS point scan measurements. Average Vickers microhardness for the as-fabricated $\mathrm{NiCrFeGeB}$ alloy was found to be $773 \pm 10 \mathrm{HV} 1$.

Figure 8 shows an average (of curves two and three) DSC cooling curve for the as-cast $\mathrm{NiCrFeGeB}$ ingot. Solidus and liquidus temperatures of $1038^{\circ} \mathrm{C}$ and $1055^{\circ} \mathrm{C}$ were determined from this. It is possible that the two phases marked 1 and 2 in Figure 7, both being

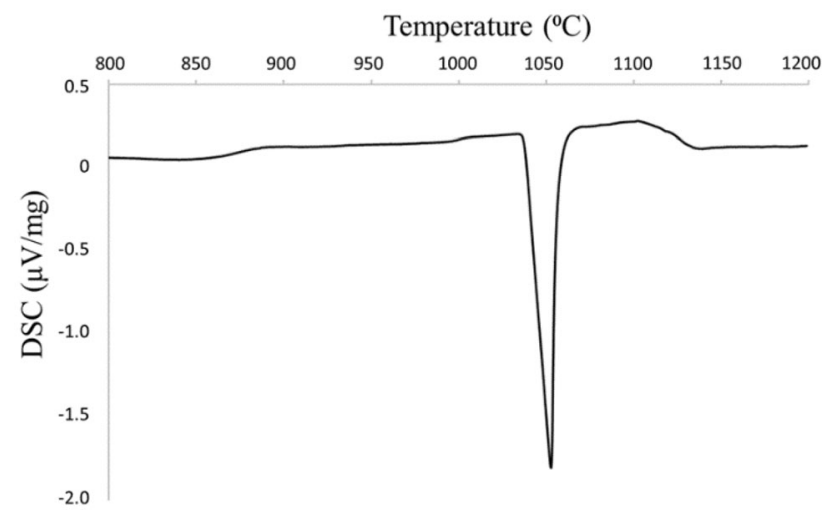

Fig. 8- Average of second and third DSC cooling curves for $30 \mathrm{mg}$ sample of the as-cast $\mathrm{NiCrFeGeB}$ alloy.

rich in $\mathrm{Cr}$, possess much higher solidus and liquidus temperatures and so no transition relating to their melting was recorded for the temperature range used in the DSC cycle. 


\section{B. Brazed Joints: Microstructure}

In this study, the trialing of the developed $\mathrm{NiCrFe}-$ $\mathrm{GeB}$ filler metal involved the use of $65-\mu \mathrm{m}$-thick foils (which were brazed at $1100{ }^{\circ} \mathrm{C}$ for hold times of 15 and 60 minutes) and $100-\mu \mathrm{m}$-thick foil (which was also brazed at $1100{ }^{\circ} \mathrm{C}$, for a hold time of 60 minutes only). This allowed evaluation of the effects of both brazing hold time and joint width on the joint microstructure when using the developed filler metal. Typical sections of the NiCrFeGeB-IN718 joint microstructures are shown in Figure 9, for both (a) 15- and (b) 60-minute braze cycles (65 $\mu \mathrm{m}$ foils). The primary microstructural difference immediately noticeable is the presence of boride phases, apparently retained from the as-cast microstructure, in the case of the 15-minute brazing time, which is not observed in the 60-minute case (marked A in Figure 9(a)). This suggests that while the 15 -minute hold time did not result in significant dissolution of these boride phases, after 60 minutes at the hold time sufficient dissolution of the boride phases had occurred. Furthermore, in both cases distinct zones containing a white-contrast phase were evident, commencing at a distance of approximately $30 \mu \mathrm{m}$ from the joint center (marked B in Figure 9(a)). This irregular, globular-shaped phase appears to primarily form along grain boundaries (GB) and EDS point scans revealed it to be rich in $\mathrm{Ni}, \mathrm{Ge}$, and $\mathrm{Nb}$, and of similar composition for both 15- and 60-minute braze cycles. The presence of $\mathrm{Nb}$ (not contained by the filler metal), and the location of the phase, indicates base metal dissolution was the primary cause of formation. As well as possessing a highly negative mixing enthalpy with the filler metal elements $\mathrm{Ni}$ and $\mathrm{Ge}, \mathrm{Nb}$ segregation is a known phenomenon in Inconel-series alloys, ${ }^{[39]}$ factors which encouraged the formation of this phase. Similarly, $\mathrm{Ni}-\mathrm{Ge}-\mathrm{Nb}$ phase was observed within the joint region for the 15-minute hold time sample (marked $\mathrm{C}$ in Figure 9(a)), attributed to rejection from advancing IS fronts, followed by the onset of cooling before IS could complete and the phase dissolved through diffusion processes. Given that this phase was not seen in the joint region for the 60-minute hold time sample, this lends credence to the notion that IS was completed in this case.

Extending approximately $50 \mu \mathrm{m}$ into the base metal from the interface are boride phases forming a relatively sparse DAZ (compared to DAZs commonly seen for B-bearing filler metals in literature). This includes GB $\mathrm{Nb}$-Mo borides, and other coarser X-borides (where $\mathrm{X}$ represents base metal elements including $\mathrm{Nb}$, Mo, and Ti) (marked D and E in Figure 9(a), respectively). The GB borides were observed generally out to a greater distance from the interface with the base metal, owing to faster diffusion along grain boundaries. While these were too fine to accurately measure with EDS point scans, EDS mapping indicated the presence of $\mathrm{Nb}$ and Mo. The X-boride phases observed were generally found to be few and far between, but were typically larger than the Nb-rich DAZ phase and of differing composition from instance to instance. The abundance of these phases was also reduced compared to similar joints using B-bearing filler metals seen in the literature. Of note is the greater concentration of GB borides in the case of the 15-minute hold time (a potential cause of which is mentioned in the discussion section). Probable fine $\mathrm{Nb}$-borides were again observed predominantly along GBs in the IS grains in the 60-minute hold time sample (marked $F$ in Figure 9(b)), but again these were too fine for EDS analysis. For both 15- and 60-minute braze cycles, the gray contrast matrix phase in the joints is the isothermally solidified Ni-rich solid solution, with noticeably reduced $\mathrm{Ge}$ content compared to the as-cast

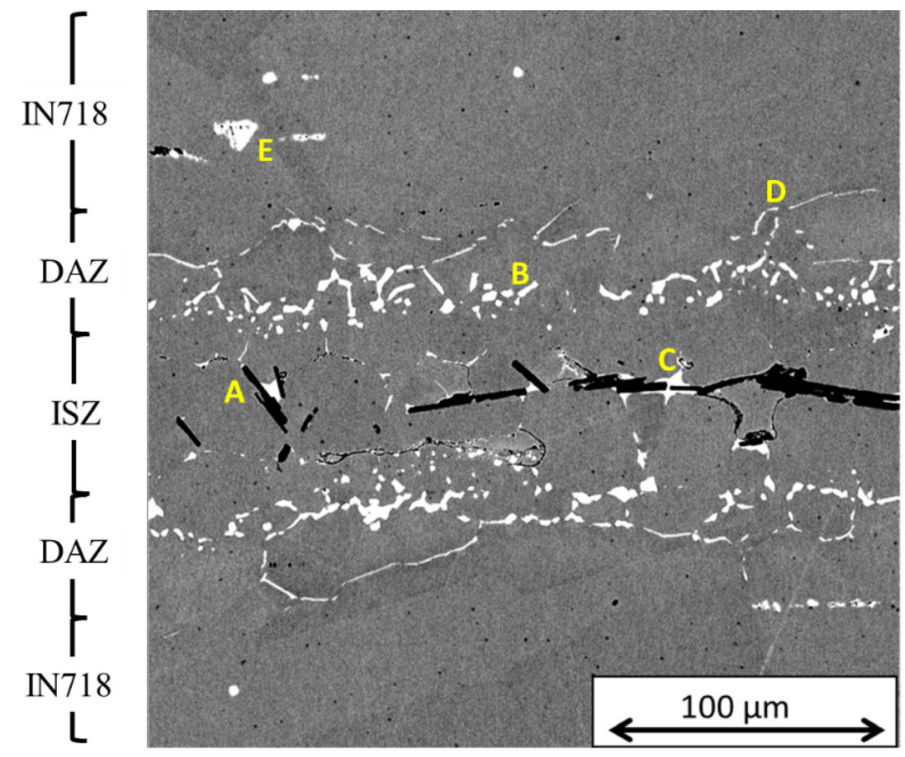

(a)

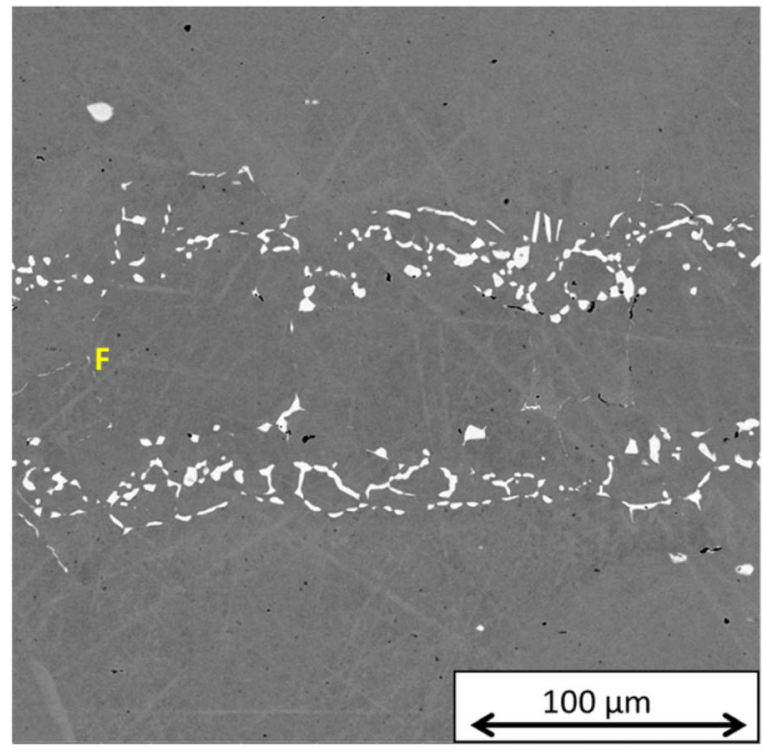

(b)

Fig. 9-SEM (BSE) micrographs of IN718-NiCrFeGeB brazed joint microstructures for; $(a)$ 15-min hold time at $1100{ }^{\circ} \mathrm{C}$; $(b) 60$-min hold time at $1100{ }^{\circ} \mathrm{C}$. Identified distinct phases marked A-F, and microstructural zones labeled (left). 
filler metal composition. Base metal elements were also observed in solution in this phase. A summary of EDS measurements of the main observed phases (A, B, C, and solid solution) is shown in Table III.

Figure 10(a) shows a typical section of the NiCrFeGeB-IN718 joint brazed for 60 minutes followed by heat treatment at an approximate service temperature of $700{ }^{\circ} \mathrm{C}$ for 100 hours, in an inert atmosphere. The microstructure is largely comparable to Figure 9(b), with the $\mathrm{Ni}-\mathrm{Ge}-\mathrm{Nb}$ phase and $\mathrm{DAZ}$ remaining largely undisturbed by the heat treatment process. Upon higher magnification (Figure 10(b)), fine GB borides are again observed in the ISZ, as marked by the arrow in Figure 10(b) (though these were on too fine a scale for quantification via EDS techniques).

Figure 11 shows a typical section of the NiCrFeGeBIN718 joint brazed using the $100 \mu \mathrm{m}$ foil for 60 minutes, with EDS measurements shown in Table IV. Immediately observable is the increased joint width, due to the initial thickness of the foil. In addition, the presence of retained boride phases (marked $\mathrm{X}$ in Figure 11) is apparent, despite the 60-minute hold time seemingly being adequate to dissolve these phases in the case of the $65-\mu \mathrm{m}$-thick foil. The borides observed in this case are typically reduced in size (under approximately $30 \mu \mathrm{m}$ ) compared to in the as-cast state of the $\mathrm{NiCrFeGeB}$ alloy, indicating some partial dissolution of these phases has occurred. Furthermore, there appears to be a reduced concentration of the $\mathrm{Ni}-\mathrm{Ge}-\mathrm{Nb}$ phase at the interface with the base metal (marked Y in Figure 11), yet an increased concentration of the white-contrast phase within the joint region (marked $\mathrm{Z}$ in Figure 11), generally close to the joint center presumably as a result of incomplete IS. An increased concentration of Nb-Mo borides was observed in the DAZ instead, extending out to between 50 to $100 \mu \mathrm{m}$ into the base metal, but this phase was not quantified by EDS point scans due to its fineness.

\section{Brazed Joints: Mechanical Properties}

Microhardness profiles taken across the brazed joints are shown in Figure 12 for each of the brazed joints (15-minute hold, 60-minute hold, 60-minute hold with $100 \mu \mathrm{m}$ foil). Little variation in microhardness was observed across the joints for all cases, with only localized changes in the joint centerline. Here, in the case of the 15-minute hold time, a sharp increase in

Table III. EDS-Determined (Average of 5-Point Measurements) Composition of Phases Identified in Fig. 9. Errors Derived From Standard Deviation of Measurements

\begin{tabular}{lrrrrrrr}
\hline & \multicolumn{6}{c}{ Element Concentration (At. Pct) } \\
\cline { 2 - 8 } Phase & $\mathrm{Ni}$ & $\mathrm{Cr}$ & $\mathrm{Fe}$ & $\mathrm{Ge}$ & $\mathrm{Nb}$ & $\mathrm{Mo}$ & $\mathrm{Ti}$ \\
\hline $\mathrm{A}$ & 1.4 & 68.7 & 6.6 & 0.4 & - & 2.1 & - \\
$\mathrm{B}$ & 39.2 & 5.7 & 5.8 & 15.6 & 24.8 & 1.1 & 1.6 \\
C & 38.5 & 11.4 & 26.3 & 27.6 & 28.8 & & \\
Solid solution & 39.9 & 25.3 & 20.8 & 10.2 & 1.2 & 1.4 & 0.4 \\
\hline
\end{tabular}

microhardness was presumably caused by the presence of retained boride. On the other hand, the 60-minute hold time sample exhibited a slight reduction across the ISZ zone, owing to the dissolution of borides phases and the joint region consisting of just Ni-rich solid solution. In the case of the $100 \mu \mathrm{m}$ foil sample, again an increase in hardness was observed, likely due to the presence of the retained boride phases near the joint center, but also possibly due to the increased presence of the $\mathrm{Ni}-\mathrm{Ge}-\mathrm{Nb}$ phase in this region.

Figure 13 shows the comparison of measured shear strengths for the three NiCrFeGeB-IN718 joints, and the BNi-2-IN718 joint. For the NiCrFeGeB filler metal, the highest shear strength was observed for the 60-minute hold time sample at $296 \mathrm{MPa}$, and the 60-minute hold time joint using the $100 \mu \mathrm{m}$ foil was only marginally weaker than this at $292 \mathrm{MPa}$. For the 15-minute hold time sample, the maximum shear strength was $269 \mathrm{MPa}$. By comparison, the joint using $\mathrm{BNi}-2$ had an average shear strength of $476 \mathrm{MPa}$.

\section{DISCUSSION}

\section{A. Alloy Design: Discrepancies Between Predictions and Observations}

In the case of many HEA and MPEA studies, the aim has been to achieve a single (or occasionally dual)-phase microstructure, either FCC or BCC, in order to achieve superior mechanical properties. In other cases, secondary precipitates may be intentionally sought in order to strike a balance between ductility and strength. However, the as-cast microstructure of the $\mathrm{NiCrFeGeB}$ MPEA in the present study was observed to possess multiple phases, two of which were likely undesirable intermetallic-type phases. As evidenced by the high microhardness measurement, this as-cast state was particularly hard and brittle due to these phases. This is despite, according to the TC predictions and empirical thermodynamic parameters in Eqs.[(1] through [3], a majority $\mathrm{FCC}$ or mixed $\mathrm{BCC} / \mathrm{FCC}$ microstructure, respectively, might have been predicted. A possible cause of this intermetallic-consisting microstructure could be found when looking at the $\Delta \mathrm{H}_{\text {mix }}$ values for specific binary pairs, in this case the Ni-Ge, Cr-Ge, and Fe-Ge pairs. These values are $-23.5,-18.5$, and $-15.5 \mathrm{~kJ} \mathrm{~mol}^{-1}$, respectively, all very negative compared to those for the binary pairs between $\mathrm{Ni}, \mathrm{Cr}$, and Fe. Therefore, despite a small, slightly positive average $\Delta \mathrm{H}_{\text {mix }}$, this is not sufficient for solid solution formation due to the dominance of the extreme values for binary pairs $\mathrm{Ni}-\mathrm{Ge}, \mathrm{Cr}-\mathrm{Ge}$, and $\mathrm{Fe}-\mathrm{Ge}$. Indeed, this also applies for explaining the presence of borides in the as-cast state.

Considering this, it appears that TC was unable to capture all the resulting phases accurately. First of all, the predictions of $\mathrm{Cr}(\mathrm{Fe})$-boride phase stand up well to the microstructural observations, though EDS did demonstrate the presence of some $\mathrm{Fe}$ in solution in these phases in the as-cast state not captured by TC. Nonetheless, the ability to predict the abundance of this 


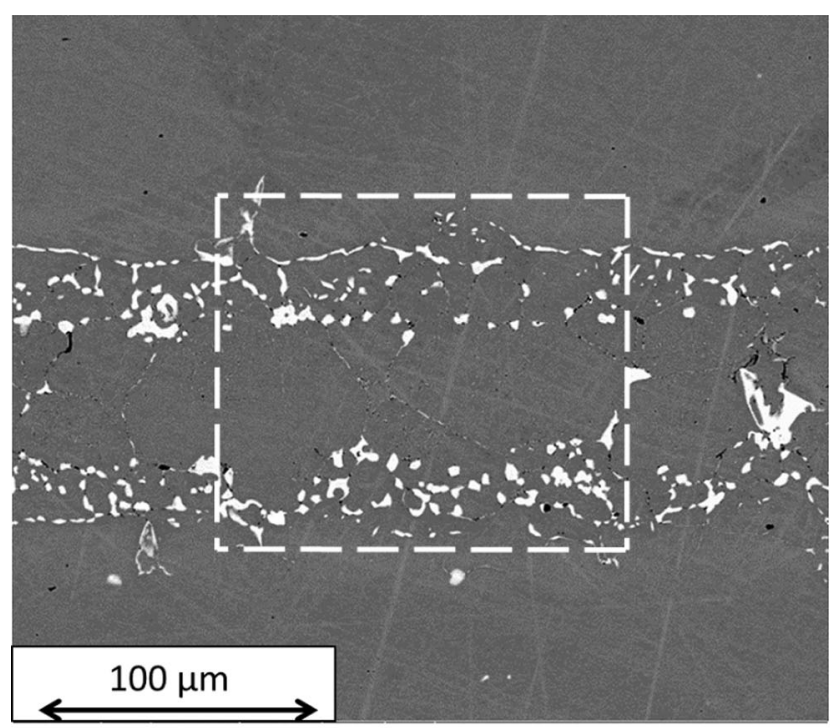

(a)

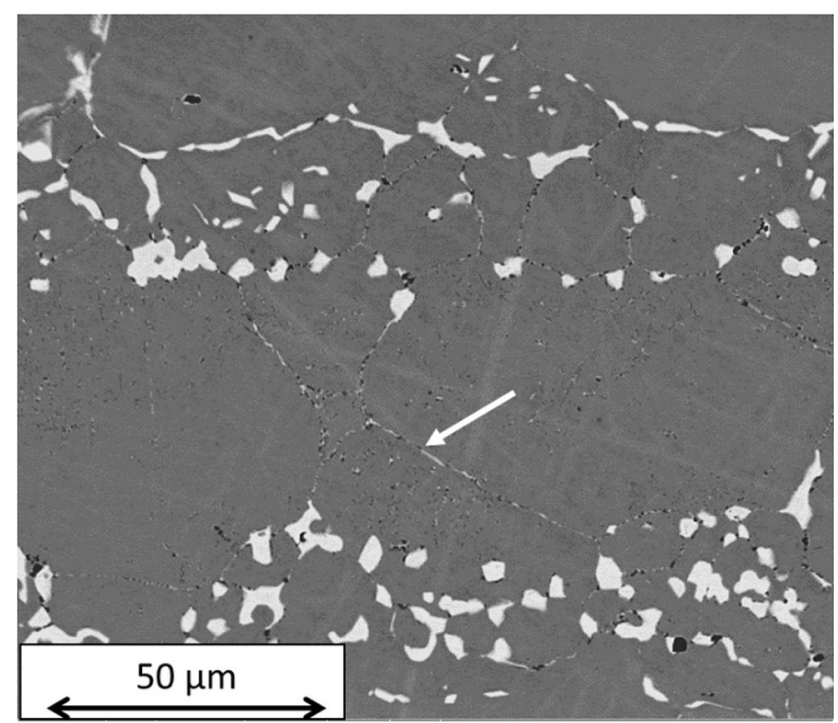

(b)

Fig. 10 - (a) SEM (BSE) micrographs of typical section of IN718-NiCrFeGeB brazed joint (60-min hold time at $1100{ }^{\circ} \mathrm{C}$ ) following heat treatment at $700{ }^{\circ} \mathrm{C}$ for 100 hours in inert atmosphere, with magnified region indicated. (b) Magnified region of part (a) with GB borides indicated with arrow.

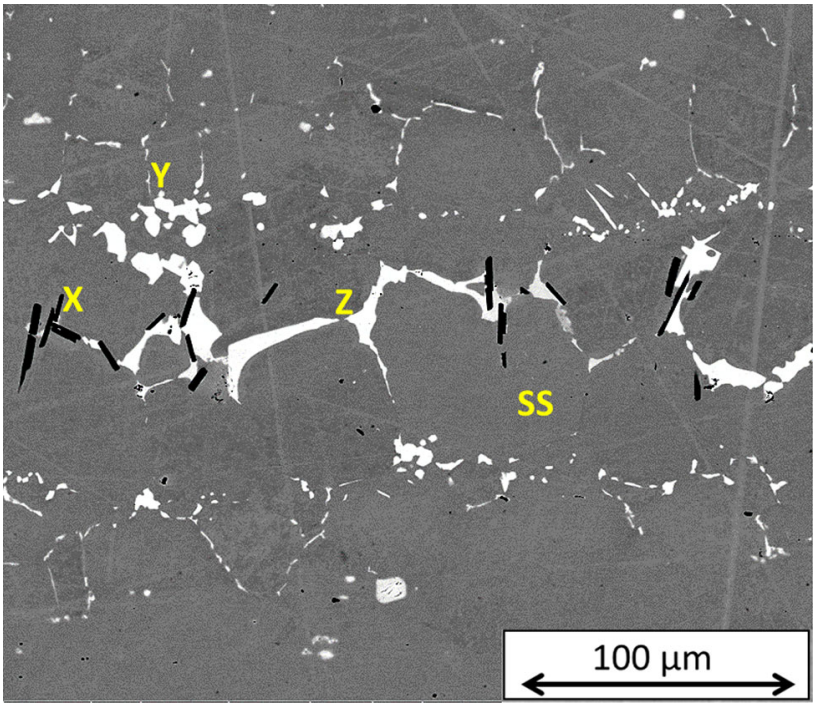

Fig. 11-SEM (BSE) micrograph of IN718-NiCrFeGeB brazed joint (60-min hold time at $1100{ }^{\circ} \mathrm{C}$ ) using $100-\mu$ m-thick foil. Solid solution phase labeled SS, with other identified distinct phases marked X, Y, and $\mathrm{Z}$.

phase is understandably useful for such alloy design applications. The other phases predicted by TC, however, were clearly not borne out in the experimental observations and demonstrates a limitation of the CALPHAD approach for such alloys, and of this SSOL4 database in particular, in that the $\mathrm{Cr}$ and $\mathrm{Ge}$ was predicted as being entirely segregated from the other phases. While perhaps less surprising in the case of
Table IV. EDS-Determined (Average of 5-Point Measurements) Composition of Phases Identified in Fig. 11. Errors Derived From Standard Deviation of Measurements

\begin{tabular}{lrrrrrrr}
\hline & \multicolumn{8}{c}{ Element Concentration (At. Pct) } \\
\cline { 2 - 8 } Phase & $\mathrm{Ni}$ & \multicolumn{1}{c}{$\mathrm{Cr}$} & \multicolumn{1}{c}{$\mathrm{Fe}$} & $\mathrm{Ge}$ & $\mathrm{Nb}$ & $\mathrm{Mo}$ & $\mathrm{Ti}$ \\
\hline $\mathrm{X}$ & 1.4 & 68.7 & 6.6 & 0.4 & - & 2.1 & - \\
$\mathrm{Y}$ & 49.4 & 3.3 & 4.8 & 22.1 & 17.9 & 1.1 & 2.2 \\
Z & 49.6 & 2.8 & 4.2 & 27.6 & 17.3 & - & 3.1 \\
Solid solution & 39.8 & 24.8 & 20.0 & 10.3 & 0.6 & 0.8 & 0.4 \\
\hline
\end{tabular}

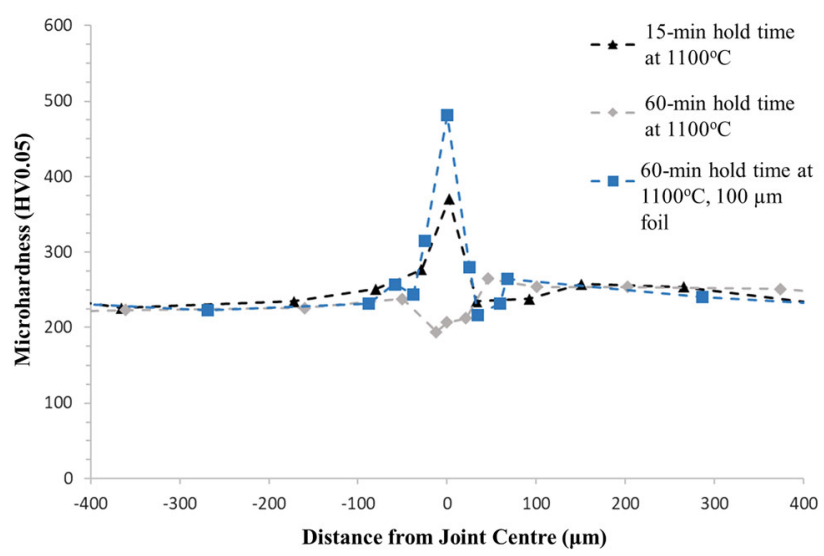

Fig. 12-Microhardness (HV0.05) profiles for different brazed joints (15-min hold time at $1100{ }^{\circ} \mathrm{C}, 60$-min hold time at $1100{ }^{\circ} \mathrm{C}$, and 15 -min hold time at $1100{ }^{\circ} \mathrm{C}$ using $100-\mu$ m-thick foil). 


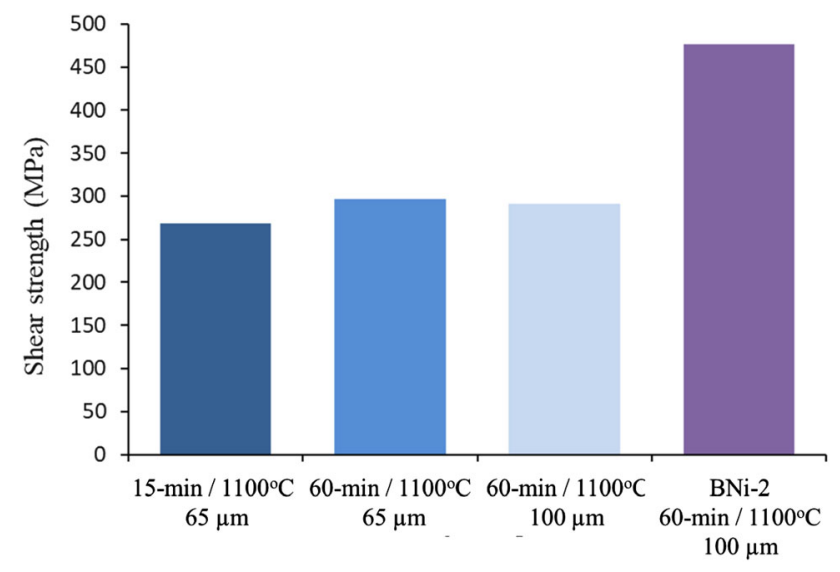

Fig. 13-Comparison of shear strengths of each joint using $\mathrm{NiCrFeGeB}$ filler alloy $\left(65 \mu \mathrm{m}\right.$ foil, 15 -min hold time at $1100{ }^{\circ} \mathrm{C} ; 65$ $\mu \mathrm{m}$ foil, 60 -min hold time at $1100{ }^{\circ} \mathrm{C} ; 100 \mu \mathrm{m}$ foil, $60-\mathrm{min}$ hold time at $1100{ }^{\circ} \mathrm{C}$ ) and the joint using commercial AWS BNi-2 filler metal.

Ge, given that assessed binary data is not available in SSOL4, it is more surprising that the $\mathrm{Cr}$ content was predicted to be completely separate from the $\mathrm{Ni}$ and $\mathrm{Fe}$ content. We see instead from the observations of the as-cast state that, aside from the aforementioned $\mathrm{Cr}(\mathrm{Fe})$-borides, the $\mathrm{Cr}$ is also in each other phase observed, and the Ge is present in each phase apart from the $\mathrm{Cr}(\mathrm{Fe})$-borides.

It is also worth noting how the predicted solidus and liquidus temperatures differ from those measured via DSC. In the case of the solidus temperature, TC predicted $816^{\circ} \mathrm{C}$, a significant discrepancy of approximately $200{ }^{\circ} \mathrm{C}$. Meanwhile, the liquidus prediction is in much more agreement with the measured liquidus, with TC predicting $1062{ }^{\circ} \mathrm{C}$ versus the DSC-measured $1055^{\circ} \mathrm{C}$. Apparently, the prediction of the $\mathrm{Cr}$ and $\mathrm{Ge}$ segregation into the $\mathrm{BCC}_{-} \mathrm{A} 2$ phase at approximately $950{ }^{\circ} \mathrm{C}$, and then the $\overline{\mathrm{G}}$ e segregation into DIAMOND_A4 phase may have depressed the prediction of the solidus temperature. Despite this discrepancy, it is still considered that TC can be useful in predicting trends on liquidus temperature, if not the exact temperatures. It is also worth noting that TC predictions are for equilibrium-state conditions (i.e., infinitely slow cooling), which is clearly not the case for the rapid cooling that occurs following arc-melting. This, in addition to the aforementioned lack of complete experimentally validated databases, means TC should be used with caution in such cases, and is better used for investigating broader changes resulting from composition changes, rather than for precise predictions.

\section{B. Brazed Joint Microstructure Analysis}

A marked change in microstructure occurs when this alloy is applied to the brazing on IN718 in this study. Brazing or transient liquid phase bonding (TLPB) is considered to be composed of a series of sequential steps in most models, which have been discussed at greater length elsewhere. ${ }^{[6]}$ Typically, these steps are as follows:

- Base metal dissolution / Liquid Homogenization
- Isothermal Solidification

- Solid Homogenization

The microstructures resulting from the described brazing cycles can be understood by considering these steps in the context of the presented results.

In each case, there has been to some extent dissolution of the base metal, as evidenced in Figures 9(a) and (b). The degree to which base metal dissolution occurs is a function of brazing temperature (a constant in this study), composition of filler and base metal (a constant), hold time, and initial joint width. Upon reaching the brazing temperature, the $\mathrm{NiCrFeGeB}$ is fully molten, and during the whole heating stage, the concentrations of MPD elements Ge and B in the solid base metal and molten filler metal follow the solidus and liquidus lines, respectively. Therefore, as the concentration of $\mathrm{Ge}$ and $\mathrm{B}$ in the liquid decreases until it reaches liquidus composition, a corresponding increase in width of the liquid occurs until the solid immediately adjacent to the liquid achieves its solidus composition. At this point, dissolution of the base metal ceases and the concentrations at the solid-liquid interface maintains this equilibrium.

After the base metal dissolution has completed, cross-diffusion of the MPD elements from filler metal and base metal elements occurs, resulting in the liquidus temperature of the melt increasing and the onset of isothermal solidification. It is considered that in this case $\mathrm{B}$ is the dominant diffusing element as its reported diffusion coefficient in Ni $\left(6.22 \times 10^{-11} \mathrm{~m}^{2} \mathrm{~s}^{-1}\right.$ as used in References 9,40) is orders of magnitude greater than for Ge $\left(4.5 \times 10^{-14} \mathrm{~m}^{2} \mathrm{~s}^{-1[33]}\right)$. This is backed up by the presence of GB-borides in the base metal at a greater distance away from the joint region, especially in the case of the 15-minute hold time. When a critical amount of the B has diffused into the base metal, grains of solidifying liquid form at the solid-liquid interface. It is believed that at this stage the $\mathrm{Ni}-\mathrm{Ge}-\mathrm{Nb}$ phases formed (white contrast on Figure 9(a)), owing to Ge rejection from the forming Ni-rich solid solution, and the large negative mixing enthalpies between $\mathrm{Ni}, \mathrm{Ge}$, and $\mathrm{Nb}$. The grain sizes of the solid solution here are notably smaller compared to those that eventually form towards the joint center as isothermal solidification proceeds. Similar findings were reported by Ghaderi et al., ${ }^{[9]}$ who attributed this to boride formation in the region close to the base metal providing a barrier to grain growth. In this case it is presumed that the $\mathrm{Ni}-\mathrm{Ge}-\mathrm{Nb}$ phase similarly hindered grain growth. This formation of the phase largely ceases abruptly and larger grains form, indicating $\mathrm{Nb}$ presence only in this region that was dissolved initially.

In the case of the 15-minute hold time, the isothermal solidification progresses to an almost complete stage, but as seen in Figure 9(a) some residual $\mathrm{Ni}-\mathrm{Ge}-\mathrm{Nb}$ phase is observed within the IS zone after brazing, again seemingly resulting from rejection from the now larger solid solution grains. In the case of the 60-minute hold time, only fine GB borides are observed in the IS zone, suggesting the prolonged hold time was sufficient for a greater degree of back-diffusion to occur after IS has 
completed. Several modeling approaches to estimating the time for isothermal solidification have been put forward and employed. Gale and Wallach ${ }^{[41]}$ and later Ojo et al. ${ }^{[42]}$ found good agreement between calculations based on Eq. [4] and experimental observations.

$$
C_{S}-C_{M}=\left(C_{0}-C_{M}\right)\left\{\operatorname{erf} \frac{w}{\sqrt{4 D t_{f}}}\right\}
$$

where $\mathrm{C}_{\mathrm{S}}, \mathrm{C}_{\mathrm{M}}$, and $\mathrm{C}_{0}$ are the MPD (B) solubility limit in the base metal, concentration in the base metal, and concentration in the filler metal, respectively; $\mathrm{w}$ is the half-width of the brazed joint; D is the MPD (B) diffusivity in the base metal; and $t_{f}$ is the time for isothermal solidification. This approach is derived from Fick's second law of diffusion and treats B as the sole solute in a simple Ni-B filler metal. This approach has, however, not been applied to cases where a HEA or MPEA is used as the filler metal. Nonetheless, it is considered appropriate to use in this case due to the evidence of $\mathrm{B}$ being the dominant diffusing element. The values used for each term in Eq. [4] are as follows:

- $\mathrm{C}_{\mathrm{S}}=0.3$ at. $\mathrm{pct}^{[41]}$ (based on Ni-B phase diagram from Reference 43)

- $\mathrm{C}_{\mathrm{M}}=0.0628$ at. pct

- $\mathrm{C}_{0}=2.5$ at. pct

- $\mathrm{w}=65 \mu \mathrm{m}$ (based on width following base metal dissolution)

- $\mathrm{D}=6.22 \times 10^{-11} \mathrm{~m}^{2} \mathrm{~s}^{-1[9,40]}$

Using Eq. [4], the expected time for IS to complete based only on B diffusion is approximately 30 minutes. This is in reasonable agreement with the experimental observations, with the 15-minute hold time being insufficient to complete IS, whereas an extra approximately 30 minutes for continued diffusion and homogenization was allowed in the case of the 60 -minute hold time.

\section{Effect of Brazing Hold Time}

The different hold times had clear effects on the degree of homogenization seen in the brazed joints. A notable difference between the 15- and 60-minute hold times was the presence, or lack, of $\mathrm{Cr}(\mathrm{Fe})$-borides apparently retained from the as-cast state. While the boride phases were observed post-braze for the 15-minute hold time with only slight size reduction, in the case of the 60-minute hold, these borides were apparently dissolved due to diffusion processes over this hold time. The retention or dissolution of these borides can be understood by considering the effect of time and temperature on the diffusion processes, and the driving force provided by the steep concentration gradient between the B-rich borides and the B-lean ISZ. The dissolution of the borides appears to have been a relatively sudden evolution, as they are only slightly reduced after the 15-minute hold time, but for the 60-minute hold time (in which IS completed), the borides were able to completely dissolve. This could be explained by the increased time for B diffusion away from the joint. Perhaps surprisingly, the B released from this dissolution did not form a significant amount of boride phases in what is usually presented as a diffusion-affected zone (DAZ). In fact, the 15-minute hold time sample exhibited a greater abundance of $\mathrm{Nb}-\mathrm{Mo}$ borides in the base metal than for the 60-minute hold time sample (which in turn exhibited a greater abundance than for the 60-minute + homogenization sample). This suggests not only that these Nb-Mo borides eventually dissolved due to increased hold time (and then to an even greater degree with subsequent homogenization), but these borides likely formed before the completion of IS rather than after, similar to findings in References 9 and 44 and contrary to the previous assumptions. ${ }^{[45]}$ It appears that only the Ni-Ge-Nb phase discussed above remained largely unchanged by either increasing the hold time or even homogenization.

\section{Effect of Increased Joint Width}

The effect of increased joint width for this filler metal was investigated through use of a $100 \mu \mathrm{m}$ foil. Despite being held for 60 minutes at the same temperature, in the case of the $100 \mu \mathrm{m}$ foil the borides were still evident post-brazing, albeit apparently reduced in size suggesting partial dissolution over the course of the braze cycle. While the initial joint width (defined by the initial foil thickness) will have an effect on the time needed to achieve complete isothermal solidification, it is not immediately apparent why the borides were not dissolved completely in this case. However, when considering the fact that the increased foil thickness results in a greater diffusion distance for B into the IN718 base metal, it can be understood that an increased concentration of B still remained in the melt when isothermal solidification commenced. Thus, the concentration gradient and hence the driving force for diffusion of $\mathrm{B}$ from boride into ISZ diminished, allowing the borides to remain.

The sample using the $100 \mu \mathrm{m}$ foil also showed differences to both $65 \mu \mathrm{m}$ foil samples in the concentration of the Ni-Ge-Nb phase (caused by base metal dissolution) and the Nb-Mo borides along grain boundaries in the base metal (caused by outward B diffusion). The concentration of the former phase is reduced at the interface with the base metal, instead observed in greater concentration within the joint due to incomplete IS. The concentration of the Nb-Mo borides, however, is increased. It is possible that the increased joint width led to a lesser degree of base metal dissolution, resulting in less of the Ni-Ge-Nb phase. An increased degree of boride dissolution then resulted in diffusion of nowfreed $\mathrm{B}$, producing the increase in $\mathrm{GB} \mathrm{Nb}-\mathrm{Mo}$ boride concentration observed.

\section{E. Chemistry of Final ISZ}

Of particular note also is the chemistry of the final ISZ in each case. As determined by the EDS analysis, the initial microstructure of the as-cast state of this alloy possessed not just the $\mathrm{Cr}(\mathrm{Fe})$-boride intermetallic, but also a $\mathrm{Cr} / \mathrm{Ge}$-rich intermetallic phase. However, unlike 
the $\mathrm{Cr}(\mathrm{Fe})$-borides this phase was not retained in the final joint microstructure. This is attributed to the large concentration gradient of $\mathrm{Ge}$ that existed between the $\mathrm{NiCrFeGeB}$ alloy and the IN718 base material, providing a high driving force for diffusion. In addition, as already mentioned, the solubility of Ge in the base metal is likely significantly greater than for B. Indeed, the grains in the ISZ were found by EDS to contain Ge in a concentration likely to be at the solubility limit. The composition of this ISZ is approximately, as expected, a HEA- or MPEA-like Ni(41)-Cr(25)-Fe(20)-Ge(10)-X (bal.) (in at. pct), with $\mathrm{X}$ being a mixture of base metal elements $\mathrm{Al}, \mathrm{Mo}, \mathrm{Nb}$, and $\mathrm{Ti}$. Both $\mathrm{TC}$ predictions and calculation of parameters $\Delta \mathrm{H}_{\text {mix }}, \delta \mathrm{r}$, and VEC suggest that this would be more likely to possess a desirable FCC structure.

\section{F. Brazed Joint Mechanical Properties}

In terms of mechanical properties, the shear strengths measured in this study are generally in line with expectation. The greatest shear strength was demonstrated for the case of the 60-minute hold time using the $65 \mu \mathrm{m}$ foil, likely due to the completion of IS, complete boride dissolution and greater degree of homogenization. The weakest shear strength was that of the 15-minute hold time using $65 \mu \mathrm{m}$ foil, likely owing to the retained borides in the joint microstructure. The 60-minute hold time using $100 \mu \mathrm{m}$ foil had the second highest measure shear strength, despite also possessing retained borides and having the largest joint width (hence least completion of IS). This sample did, however, possess a lower concentration of the $\mathrm{Ni}-\mathrm{Ge}-\mathrm{Nb}$ phase at the base metal interfaces as compared to both the samples that used $65 \mu \mathrm{m}$ foils. This perhaps counteracted some of the detrimental effect of the retained boride phases, enough to achieve a strength greater than that for the 15-minute hold time, but not greater than that for the 60-minute hold time. Compared to the commercially available AWS BNi-2 filler metal, which achieved an average shear strength of 476 $\mathrm{MPa}$ in this study, the shear strengths achieved by the $\mathrm{NiCrFeGeB}$ filler metal in each trial was weaker, the highest being $296 \mathrm{MPa}$. In the literature, strengths of often over $500 \mathrm{MPa}$ may be reached for $\mathrm{BNi}-2$, using comparable brazing cycles. Pouranvari et al. achieved a shear strength of approximately $580 \mathrm{MPa}$ when brazing IN718 with AWS BNi-2 at $1100{ }^{\circ} \mathrm{C}$ with a 60 -minute hold time. ${ }^{[46]}$ Nonetheless, this is a promising result when considering further optimization that may be made to the alloy. Indeed, the findings suggest that the joint width in the NiCrFeGeB-IN718 joints does not have a large impact on the shear strength, and may be less sensitive to joint width than current filler metals such as BNi-2. This may have a potential benefit in situations where joint gap is hard to control, such as in repair, or in the joining of components with rough surface finish, such as additively manufactured parts. While not all conceived applications of this alloy would require such strengths as this (for example, this alloy may be useful in applications requiring corrosion resistance rather than high strength), it is worth considering that the strength may be increased by composition optimization in order to achieve a more ductile ISZ phase, perhaps by reducing Ge content, at the slight cost of increasing liquidus, to some degree.

\section{CONCLUSIONS}

In the present study, a novel NiCrFeGeB MPEA-derived filler metal was designed using TC software and empirical thermodynamic parameters employed in the design of HEAs. The designed alloy was used, in the form of $65-\mu \mathrm{m}$-thick foil, to braze nickel-based superalloy IN718 at $1100{ }^{\circ} \mathrm{C}$ for both 15 minutes and 60 minutes. The stability under approximate service conditions $\left(700{ }^{\circ} \mathrm{C}\right.$ for 100 hours) was also investigated. A further trial was conducted at $1100{ }^{\circ} \mathrm{C}$ for 60 minutes using a $100-\mu \mathrm{m}$-thick foil to investigate the effect of increased joint width. The main findings can be summarized as follows:

- TC predictions of the as-cast $\mathrm{NiCrFeGeB}$ alloy microstructure had mixed accuracy. While Cr-borides were captured by the predictions, the lack of experimentally established data for Ge-containing binary systems appeared to limit the accuracy of the predictions. Predictions for the alloy solidus temperature were significantly different to that measured by DSC, while the liquidus prediction differed from that measured by only a $3^{\circ} \mathrm{C}$. TC is best used to investigate broad trends during alloy development rather than to use for precise predictions.

- Contrary to most of the TC predictions and empirical thermodynamic parameters, the as-cast alloy was characterized by $\mathrm{Cr}(\mathrm{Fe})$-borides and a $\mathrm{Cr}-\mathrm{Ge}$ rich intermetallic phase, in addition to two other phases, one Ni-rich and one Ge-rich. This is likely due to the very negative $\Delta \mathrm{H}_{\text {mix }}$ between binary pairs of $\mathrm{Ni}, \mathrm{Cr}$, and $\mathrm{Fe}$ with $\mathrm{Ge}$ and $\mathrm{B}$, which overrules the average $\Delta \mathrm{H}_{\text {mix }}$ of all binary pairs which was calculated as slightly positive.

- Base metal dissolution resulted in the formation of a $\mathrm{Ni}-\mathrm{Ge}-\mathrm{Nb}$-rich phase in the vicinity of the interfaces with the base metal in all samples.

- Isothermal solidification was completed to varying degrees depending on hold time and joint width. IS was incomplete for the 15-minute hold time and the $100-\mu$ m-thick foil samples, both exhibiting residual rejected $\mathrm{Ni}-\mathrm{Ge}-\mathrm{Nb}$ phase in the joint. IS was completed for the 60-minute hold time sample, with IS grains spanning the original gap width. These grains (in all samples) possessed an FCC Ni-rich, HEA-like composition. In the case of the 15-minute hold time and the 100- $\mu$ m-thick foil samples, $\mathrm{Cr}(\mathrm{Fe})$-borides, apparently retained from the as-cast microstructure, were observed post braze. This was attributed to the insufficient time at temperature for the former case, and to the increased joint width in the latter case.

- Shear strengths of the NiCrFeGeB brazed joints ranged from $269 \mathrm{MPa}$ (15-minute hold, $65 \mu \mathrm{m}$ foil) to $296 \mathrm{MPa}$ (60-minute hold, $65 \mu \mathrm{m}$ foil). Using the 
increased thickness of $100 \mu \mathrm{m}$ foil resulted in only a small decrease in joint shear strength.

\section{ACKNOWLEDGEMENTS}

LH gratefully acknowledges the financial support of VBC Group and the Engineering and Physical Sciences Research Council (EPSRC) UK, through the Centre for Doctoral Training in Advanced Metallic Systems.

\section{OPEN ACCESS}

This article is licensed under a Creative Commons Attribution 4.0 International License, which permits use, sharing, adaptation, distribution and reproduction in any medium or format, as long as you give appropriate credit to the original author(s) and the source, provide a link to the Creative Commons licence, and indicate if changes were made. The images or other third party material in this article are included in the article's Creative Commons licence, unless indicated otherwise in a credit line to the material. If material is not included in the article's Creative Commons licence and your intended use is not permitted by statutory regulation or exceeds the permitted use, you will need to obtain permission directly from the copyright holder. To view a copy of this licence, visit http://creat ivecommons.org/licenses/by $/ 4.0 /$.

\section{REFERENCES}

1. C. Briant \& E. Hall: Welding Research Supplement, 1990, pp. 60-67.

2. D. Bose, A. Datta, A. Rabinkin \& N. J. De Cristofaro: Welding Research Supplement, 1986, pp. 23-30.

3. M. Salmaliyan and M. Shamanian: Heat Mass Transf., 2019, vol. 55 (8), pp. 2083-93.

4. X.J. Yuan, M.B. Kim, and C.Y. Kang: Mater. Sci. Technol., 2011, vol. 27 (7), pp. 1191-97.

5. M. Abdelfatah and O.A. Ojo: Mater. Sci. Technol., 2009, vol. 25 (1), pp. 61-67.

6. W.F. Gale and D.A. Butts: Sci. Technol. Weld. Joining, 2004, vol. 9 (4), pp. 283-300.

7. A. Ghasemi and M. Pouranvari: Sci. Technol. Weld. Joining, 2019, vol. 23 (5), pp. 441-48.

8. A. Amirkhani, B. Beidokhti, K. Shirvani, and M.R. Rahimipour: J. Mater. Process. Technol., 2019, vol. 266, pp. 1-9.

9. S. Ghaderi, F. Karimzadeh, and A. Ashrafi: J. Manuf. Process., 2020, vol. 49, pp. 162-74.

10. A. Yarmou Shamsabadi, R. Bakhtiari, and B.G. Eisaabadi: $J$. Alloys Compds., 2016, vol. 685, pp. 896-904.

11. J. Chen, V. Demers, E.L. Cadotte, D. Turner, and P. Bocher: $J$. Mater. Eng. Perform., 2017, vol. 26 (2), pp. 547-53.

12. K.A. Rozman, M.A. Carl, M. Kapoor, N. Doğan, and J.A. Hawk: Mater. Sci. Eng. A, 2019, vol. 768, p. 138477.

13. S.Y. Wang, Y. Sun, X.Y. Hou, C.Y. Cui, X.F. Sun, and Y.Z. Zhou: Mater. Lett., 2020, vol. 258, art. no. 126730.

14. M. K. Dinkel, P. Heinz, F. Pyczak, A. Volek, M. Ott, E. Affeldt, A. Vossberg, M. Göken, R. F. Singer: TMS Proceedings of the International Symposium on Superalloys, 2008, pp. 211-20.
15. B. Laux, S. Piegert, and J. Rösler: Metall. Mater. Trans. A, 2009, vol. 40A, pp. 138-49.

16. J.W. Yeh, S.K. Chen, S.J. Lin, J.Y. Gan, T.S. Chin, T.T. Shun, C.H. Tsau, and S.Y. Chang: Adv. Eng. Mater., 2004, vol. 6 (5), pp. 299-303.

17. D.B. Miracle: Nat. Commun., 2019, vol. 10 (1), pp. 1-3.

18. P.-K. Huang, J.-W. Yeh, T.-T. Shun, and S.-K. Chen: Adv. Eng. Mater., 2004, vol. 6 (1), pp. 74-78.

19. D.B. Miracle and O.N. Senkov: Acta Mater., 2017, vol. 122, pp. $448-511$

20. X. Gao, Y. Lu, B. Zhang, N. Liang, G. Wu, G. Sha, J. Liu, and Y. Zhao: Acta Mater., 2017, vol. 141, pp. 59-66.

21. Y. Zou, J.M. Wheeler, H. Ma, P. Okle, and R. Spolenak: Nano Lett., 2017, vol. 17 (3), pp. 1569-74.

22. O.N. Senkov, J.M. Scott, S.V. Senkova, D.B. Miracle, and C.F. Woodward: J. Alloy Compd., 2011, vol. 509 (20), pp. $6043-48$.

23. X.W. Qiu, Y.P. Zhang, L. He, and C.G. Liu: J. Alloy Compd., 2013, vol. 549, pp. 195-99.

24. C. Shang, E. Axinte, W. Ge, Z. Zhang, and Y. Wang: Surf. Interfaces, 2017, vol. 9, pp. 36-43.

25. B. Gorr, M. Azim, H.J. Christ, T. Mueller, D. Schliephake, and M. Heilmaier: J. Alloy Compd., 2015, vol. 624, pp. 270-78.

26. D. Bridges, S. Zhang, S. Lang, M. Gao, Z. Yu, Z. Feng, and A. Hu: Mater. Lett., 2018, vol. 215, pp. 11-14.

27. W. Tillmann, L. Wojarski, M. Manka \& C. Timmer: Proceedings from the International Brazing \& Soldering Conference, 2018, pp. $142-48$.

28. M. Gao, B. Schneiderman, S.M. Gilbert, and Z. Yu: Metall. Mater. Trans. A, 2019, vol. 50A (11), pp. 5117-27.

29. S. Jin, C. Leinenbach, J. Wang, L.I. Duarte, S. Delsante, G. Borzone, A. Scott, and A. Watson: Calphad, 2012, vol. 38, pp. 23-34.

30. Y.Q. Liu and Y. Du: Comput. Coupling Phase Diagr. Thermochem., 2010, vol. 34, pp. 25-36.

31. H. Okamoto: J. Phase Equilib. Diffus., 2008, vol. 29, p. 292.

32. G.V. Raynor and V.G. Rivlin: Phase Equilibria in Iron Ternary Alloys, The Institute of Metals, London, 1988, pp. 316-32.

33. R. Rettig, S. Steuer, and R.F. Singer: J. Phase Equilib. Diffus., 2011, vol. 32 (3), pp. 198-205.

34. Y. Zhang, Y.J. Zhou, J.P. Lin, G.L. Chen, and P.K. Liaw: $A d v$. Eng. Mater., 2008, vol. 10 (6), pp. 534-38.

35. M.C. Troparevsky, J.R. Morris, Y. Wang, A.R. Lupini, and G. Malcolm: J. Miner. Met. Mater. Soc., 2015, vol. 67 (10), pp. $2350-63$.

36. S. Guo, C. Ng, J. Lu, and C.T. Liu: J. Appl. Phys., 2011, vol. 109, p. 103505.

37. S. Guo and C.T. Liu: Prog. Nat. Sci. Mater. Int., 2011, vol. 21 (6), pp. 433-46.

38. K. Matsu, Y. Miyazawa, Y. Nishi, and T. Ariga: Mater. Trans., 2007, vol. 48 (5), pp. 1055-59.

39. W.C. Liu, M. Yao, Z.L. Chen, and S.G. Wang: J. Mater. Sci., 1999, vol. 34, pp. 2583-86.

40. M. Pouranvari, A. Ekrami, and A.H. Kokabi: J. Alloy. Compd., 2013, vol. 563, pp. 143-149.

41. W.F. Gale and E.R. Wallach: Mater. Sci. Technol. (U.K.), 1991, vol. 7 (12), pp. 1143-48.

42. O.A. Ojo, N.L. Richards, and M.C. Chaturvedi: Sci. Technol. Weld. Join., 2004, vol. 9 (6), pp. 532-40.

43. T. B. Massalski, J. L. Murray \& L. H. Bennet: Binary alloy phase diagrams: Volume 1 In ASM International, ASM, Metals Park, Ohio, 1986, pp. 366-71.

44. W.F. Gale and E.R. Wallach: Metall. Trans. A, 1991, vol. 22, pp. 2451-57.

45. I. Tuah-Poku, M. Dollar, and T.B. Massalski: Metall. Trans. A, 1988, vol. 19, pp. 675-86.

46. M. Pouranvari, A. Ekrami, and A.H. Kokabi: Mater. Sci. Technol. (U.K.), 2014, vol. 30 (1), pp. 109-15.

Publisher's Note Springer Nature remains neutral with regard to jurisdictional claims in published maps and institutional affiliations. 